\title{
Article \\ Spinal Excitatory Dynorphinergic Interneurons Contribute to Burn Injury-Induced Nociception Mediated by Phosphorylated Histone 3 at Serine 10 in Rodents
}

\author{
Angelika Varga ${ }^{1,2, *}$, Zoltán Mészár ${ }^{2}$, Miklós Sivadó ${ }^{1,2}$, Tímea Bácskai ${ }^{3}$, Bence Végh ${ }^{2}$, Éva Kókai ${ }^{1,2}$, \\ István Nagy ${ }^{4,5}$ and Péter Szücs ${ }^{1,2}$
}

check for

updates

Citation: Varga, A.; Mészár, Z.; Sivadó, M.; Bácskai, T.; Végh, B.; Kókai, É.; Nagy, I.; Szücs, P. Spinal Excitatory Dynorphinergic Interneurons Contribute to Burn Injury-Induced Nociception Mediated by Phosphorylated Histone 3 at Serine 10 in Rodents. Int. J. Mol. Sci. 2021, 22, 2297. https://doi.org/ $10.3390 /$ ijms 22052297

Academic Editor: Zsuzsanna Helyes

Received: 8 January 2021

Accepted: 21 February 2021

Published: 25 February 2021

Publisher's Note: MDPI stays neutral with regard to jurisdictional claims in published maps and institutional affiliations.

Copyright: (c) 2021 by the authors. Licensee MDPI, Basel, Switzerland. This article is an open access article distributed under the terms and conditions of the Creative Commons Attribution (CC BY) license (https:// creativecommons.org/licenses/by/ $4.0 /$ )
1 MTA-DE-NAP B-Pain Control Research Group, University of Debrecen, 4032 Debrecen, Hungary; miklos.sivado@anat.med.unideb.hu (M.S.); kokai.eva@med.unideb.hu (É.K.); szucs.peter@med.unideb.hu (P.S.)

2 Department of Anatomy, Histology and Embryology, Faculty of Medicine, University of Debrecen, 4032 Debrecen, Hungary; meszarz@anat.med.unideb.hu (Z.M.); vegbence1997@gmail.com (B.V.)

3 Division of Dental Anatomy, Department of Basic Medical Sciences, Faculty of Dentistry, University of Debrecen, 4032 Debrecen, Hungary; bacskai.timea@anat.med.unideb.hu

4 Department of Surgery and Cancer, Imperial College London, London SW7 ZAZ, UK; i.nagy@imperial.ac.uk

5 Department of Physiology, Faculty of Medicine, University of Debrecen, 4032 Debrecen, Hungary

* Correspondence: varga.angelika@med.unideb.hu; Tel.: +36-(52)-255-567

\begin{abstract}
The phosphorylation of serine 10 in histone 3 (p-S10H3) has recently been demonstrated to participate in spinal nociceptive processing. However, superficial dorsal horn (SDH) neurons involved in p-S10H3-mediated nociception have not been fully characterized. In the present work, we combined immunohistochemistry, in situ hybridization with the retrograde labeling of projection neurons to reveal the subset of dorsal horn neurons presenting an elevated level of p-S10H3 in response to noxious heat $\left(60^{\circ} \mathrm{C}\right)$, causing burn injury. Projection neurons only represented a small percentage $(5 \%)$ of $\mathrm{p}-\mathrm{S} 10 \mathrm{H} 3$-positive cells, while the greater part of them belonged to excitatory $\mathrm{SDH}$ interneurons. The combined immunolabeling of $\mathrm{p}-\mathrm{S} 10 \mathrm{H} 3$ with markers of already established interneuronal classes of the SDH revealed that the largest subset of neurons with burn injuryinduced p-S10H3 expression was dynorphin immunopositive in mice. Furthermore, the majority of p-S10H3-expressing dynorphinergic neurons proved to be excitatory, as they lacked Pax-2 and showed Lmx1b-immunopositivity. Thus, we showed that neurochemically heterogeneous SDH neurons exhibit the upregulation of p-S10H3 shortly after noxious heat-induced burn injury and consequential tissue damage, and that a dedicated subset of excitatory dynorphinergic neurons is likely a key player in the development of central sensitization via the p-S10H3 mediated pathway.
\end{abstract}

Keywords: histone; epigenetic modification; superficial dorsal horn neuron; burn injury; neuropeptides; nociception

\section{Introduction}

There is growing interest in epigenetic mechanisms of gene regulation as processes that regulate the development and maintenance of pain of various origins [1,2]. A wide array of epigenetic processes are being considered, including the modification of histones by acetylation [1,2] and phosphorylation [3,4]. Changes in gene expression are particularly important in spinal dorsal horn (SDH) neurons as, together with glial cells, they form circuitries that are pivotal for the first stage processing of nociceptive information $[5,6]$. Despite accumulating data from novel experimental strategies [7-10], our understanding of those circuitries, and hence of spinal nociceptive information processing, is still very limited. Therefore, the further thorough characterization of SDH neurons using new strategies is needed. The recently identified marker, phosphorylated (p) serine 10 (S10) in histone 3 (H3), an epigenetic tag that exhibits upregulation in a group of SDH neurons following 
various injuries and subsequent inflammation of peripheral tissues, may be used as part of such needed new strategies $[3,4]$. The phosphorylation of S10 in H3 is a permissive histone post-translational modification (PTM) that allows for the transcription of various early genes including $c$-Fos, which then act as transcription factors regulating the transcription of pain-related secondary response genes in the spinal cord of rodents [3,4]; however, c-Fos is expressed in a much broader set of SDH neurons [11,12]. Additionally, blocking the writer of phosphorylation of S10 in $\mathrm{H} 3$ specifically results in the lack of development of an important modality, heat hyperalgesia, and in prolonged pain associated with inflammation of tissues [3,4]. Hence, characterizing p-S10H3-expressing SDH neurons and the genes that are directly or indirectly controlled by that epigenetic tag would lead us to better understanding how SDH circuitries are involved in the development of hypersensitivity to heat in inflammatory conditions work.

Based on neurokinin-1 receptor (NK1R) expression, SDH neurons exhibiting upregulation in $\mathrm{p}-\mathrm{S} 10 \mathrm{H} 3$ expression following tissue injury/inflammation are regarded as putative projection neurons (PNs) with axons terminating in supraspinal areas [3]. While projection neurons of the SDH are all glutamatergic, SDH interneurons are either excitatory or inhibitory in function [5,13-16]. Based on their neurochemical properties, both excitatory and inhibitory neurons can further be divided into smaller, though somewhat overlapping groups of neurons; while excitatory cells are divided into somatostatin (SOM), neurotensin, neurokinin $\mathrm{B}$, cholecystokinin (CCK), substance P (SP), gastrin-releasing peptide (GRP) and neuropeptide FF (NPFF)-expressing groups; inhibitory cells contain parvalbumin (PV), calretinin (CR), neuropeptide Y (NPY), neuronal nitrogen monoxide synthase (nNOS) or dynorphin (Dyn)/galanin [5,16-26]. Thus, in order to link the diverse $\mathrm{SDH}$ neuronal populations to the $\mathrm{p}-\mathrm{S} 10 \mathrm{H} 3$-mediated re-organization of spinal nociceptive circuitries, we have used burn injury to induce tissue damage and assessed the neurochemical properties and distribution of SDH neurons that exhibited consequential upregulation in $\mathrm{p}-\mathrm{S} 10 \mathrm{H} 3$ expression.

\section{Results}

2.1. $p$-S10H3 Expression is Upregulated in a Subpopulation of Ipsilateral SDH Neurons with Differing Rostrocaudal Density Following Burn Injury

While innocuous stimulation $\left(37^{\circ} \mathrm{C}\right.$ for $2 \mathrm{~min}$ ) did not induce the phosphorylation of $\mathrm{S} 10 \mathrm{H} 3$ in the SDH (Figure 1a), in agreement with Torres-Perez et al. [4] there were numerous p-S10H3-labeled nuclei in the entire mediolateral extent of the ipsilateral laminae I-IIo 5 min after tissue damage induced by heat insult to the hind paw $\left(60^{\circ} \mathrm{C}\right.$ for $2 \mathrm{~min}$; Figure $1 \mathrm{~b}$; Table 1). All lumbar segments (L1-L6) contained p-S10H3-immunoreactive nuclei following burn injury, however, there was a significant difference in the number of neurons expressing p-S10H3 between rostral (L1-L3) and caudal (L4-L6) segments (Figure 1c). The highest number of p-S10H3 nuclei was encountered in the L6 spinal segment, which corresponded to the somatotopic origin of the stimulus applied to the distal part of the hind limb, and the number of $\mathrm{p}-\mathrm{S} 10 \mathrm{H} 3$ nuclei declined gradually towards the L1 segment (values correspond to the medians on the box plot; Figure 1c, Table 1; four to nine sections per segment from three animals). The estimated total number of neurons showing p-S10H3 in the lumbar region (L1 to L6) was $1452.2 \pm 222$ (four to nine sections per segment from three animals). 

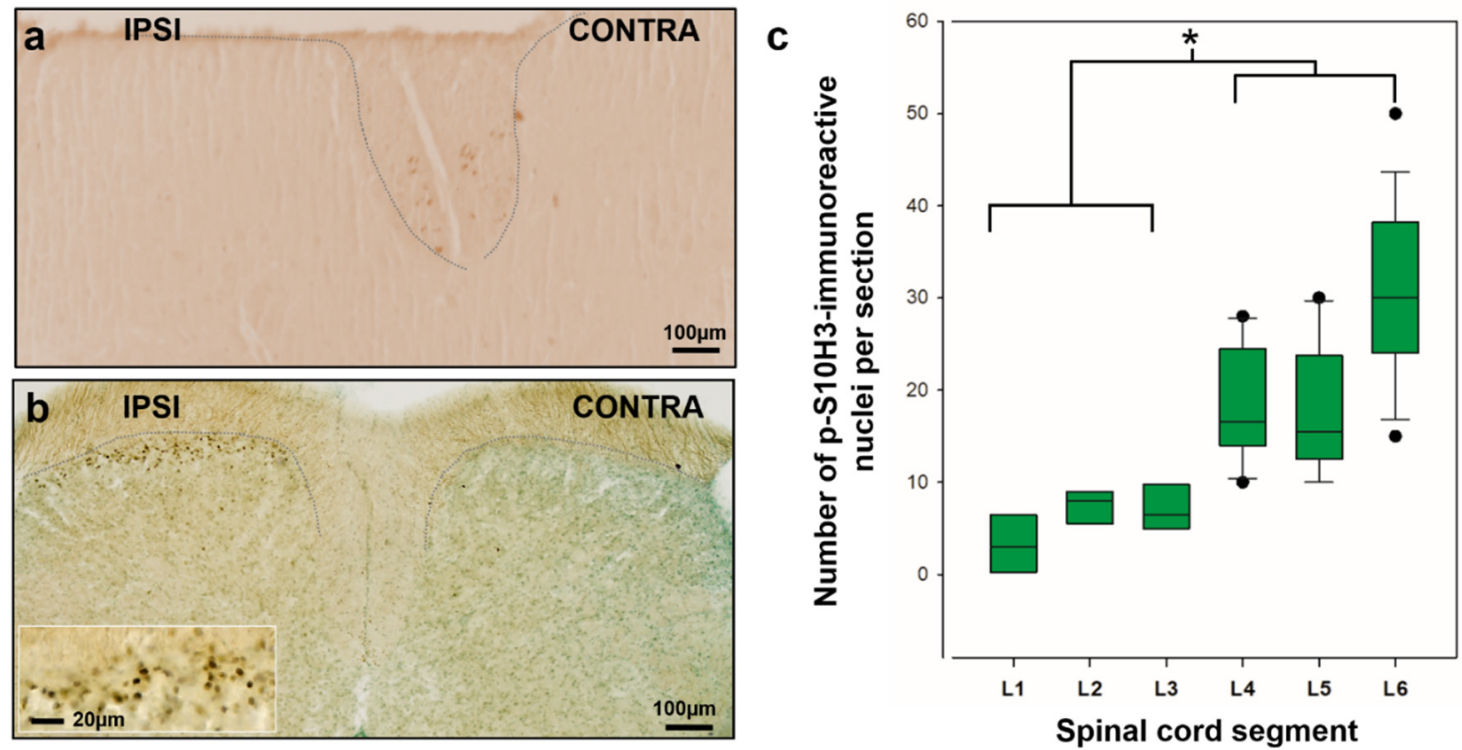

Spinal cord segment

Figure 1. Burn injury-induced $\mathrm{S} 10 \mathrm{H} 3$ phosphorylation is mainly located in the superficial dorsal horn (SDH) and displays unequal distribution within the spinal lumbar segments (L1-L6) in mice. (a) Innoxious stimulation ( $37^{\circ} \mathrm{C}$ for $2 \mathrm{~min}$ ) did not induce the phosphorylation of $\mathrm{S} 10 \mathrm{H} 3$ in the SDH. (b) Burn injury $\left(60^{\circ} \mathrm{C}\right.$ for $2 \mathrm{~min}$ ) induced a robust phosphorylation of $\mathrm{S} 10 \mathrm{H} 3$ in the ipsilateral SDH only. Both sections $(\mathbf{a}, \mathbf{b})$ were taken from L5 spinal segments. Dotted lines indicate the border between gray and white matter. (c) Burn injury-induced p-S10H3 expression shows unequal rostrocaudal distribution, with a peak expression in L6. Data presented as box plots are from $80-\mu \mathrm{m}$-thick sections taken from each segment (4-9 sections per segment from 3 animals). Dots indicate outlier values. ${ }^{*} p<0.05$.

Table 1. Evaluation of the total number of p-S10H3-positive neurons in each lumbar segment (L6-L1) of mouse spinal cord following burn injury ( $\mathrm{n}=3$ mice).

\begin{tabular}{|c|c|c|c|c|c|c|}
\hline & L6 & L5 & L4 & L3 & L2 & L1 \\
\hline Mean number of p-S10H3-positive neurons $\#$ & $30.7 \pm 3.1$ & $17.7 \pm 2.7$ & $18.5 \pm 2.3$ & $7.5 \pm 1.5$ & $7.5 \pm 0.8$ & $3.25 \pm 2.7$ \\
\hline Thickness of a given segment in $\mathrm{mm} *$ & 1.45 & 1.18 & 1.31 & 1.45 & 1.58 & 1.31 \\
\hline Number of $80 \mu \mathrm{m}$-thick sections per segment ${ }^{£}$ & 18.1 & 14.7 & 16.3 & 18.1 & 19.2 & 16.3 \\
\hline Total number of p-S10H3+ neurons per segment $€$ & $557 \pm 57$ & $260.9 \pm 40$ & $301.5 \pm 38$ & $135.7 \pm 28$ & $144 \pm 17$ & $52.9 \pm 44$ \\
\hline
\end{tabular}

\# calculated from $2-4$ sections per 3 mice. ${ }^{*}$ based on a study from Harrison et al. [27]. ${ }^{£}$ thickness of a given segment was divided by the thickness of sections $(80 \mu \mathrm{m}) .{ }^{\epsilon}$ total number of $\mathrm{p}-\mathrm{S} 10 \mathrm{H} 3$-positive neurons per segment was calculated as follows: mean number of p-S10H3-positive neurons ( \pm SEM) was multiplied by the number of $80 \mu \mathrm{m}$ thick sections per segment.

\subsection{SDH Neurons Expressing p-S10H3 Following Burn Injury are in Close Apposition Mainly to CGRP-Containing Peptidergic Afferents}

It is well-known that there is only limited overlap between isolectin B4 (IB4) and CGRP-positive primary afferent terminals in the superficial laminae due to their different laminar arborization derived from their differing sensory functions [28,29]. As expected, somata containing p-S10H3 restricted to lamina I and Ilo were largely overlapping with the CGRP-positive area both in mice (Figure 2(a1)) and rats (Figure 2c), while p-S10H3containing neurons in the superficial dorsal horn typically did not fall within the area occupied by IB4 terminals or within deeper laminae in either species (Figure 2b-d). Putative synaptic contacts from CGRP-immunopositive (IP) terminals could also be observed on the soma of p-S10H3-containing neurons (Figure 2(a2)). Of the total p-S10H3-positive nuclei, $84 \%(197 / 235)$ and $11 \%(27 / 235)$ were located within the CGRP- and IB4-immunoreactive (IR) area in mice, respectively (Figure $2 \mathrm{~d}$ ). Similarly, in rats, $84 \%$ of total p-S10H3 nuclei occupied the area of CGRP terminals $(217 / 257)$, whereas only $11 \%$ were present in lamina IIi which is innervated by IB4 (29/257; Figure 2d). 

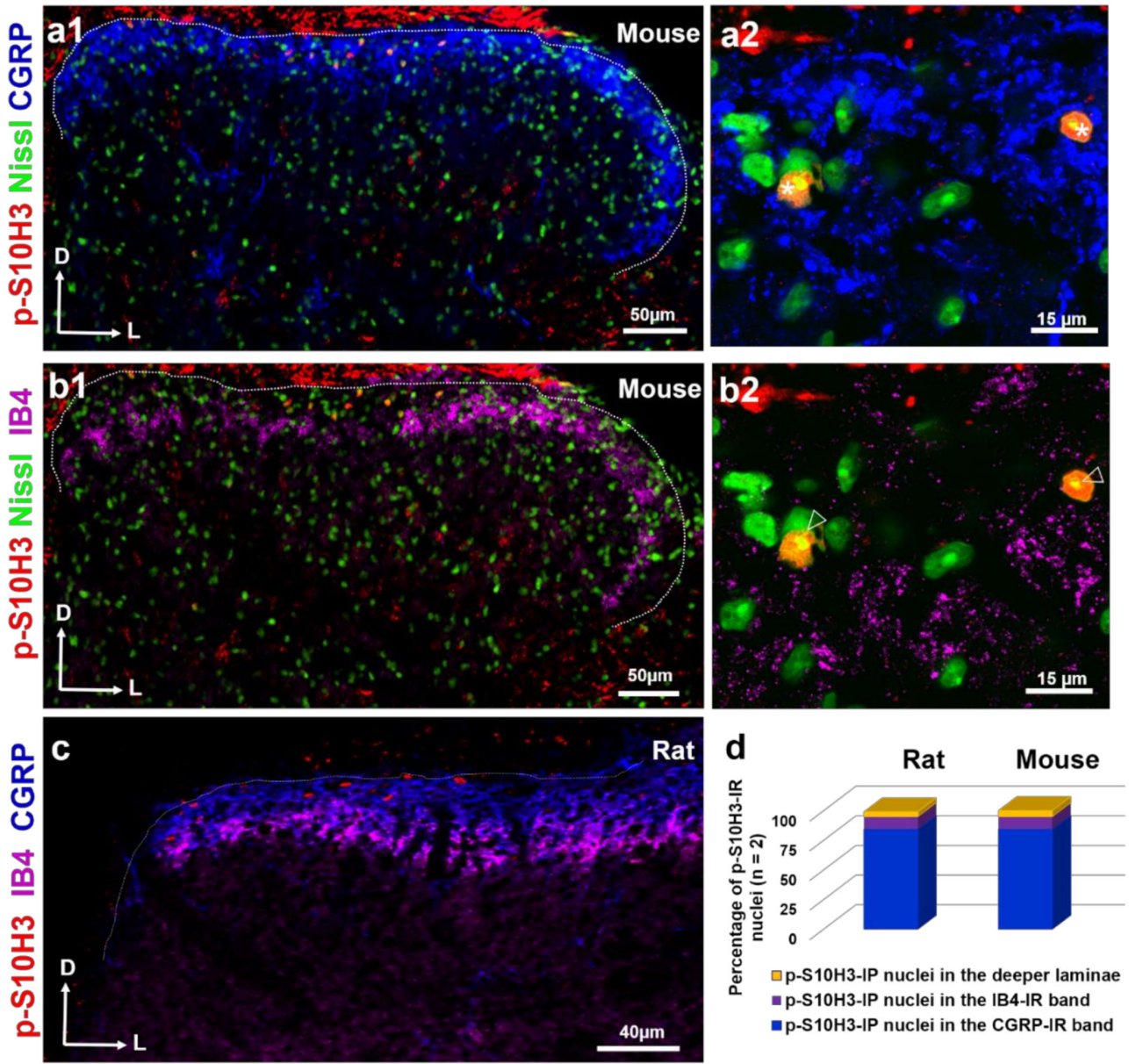

Figure 2. Neurons in the superficial dorsal horn exhibiting p-S10H3 immunoreactivity after burn injury show close appositions with CGRP-containing peptidergic afferents. (a1,a2) Immunostaining with antibodies against p-S10H3 (red), CGRP (blue) and Nissl (green). (a2) Asterisks indicate p-S10H3-positive neurons presenting close appositions with CGRPcontaining peptidergic terminals. (b1,b2) Immunostaining with antibodies against p-S10H3 (red), isolectin B4 (IB4) (purple) and Nissl (green). (b2) None of the three p-S10H3-immunopositive neurons (empty arrowheads) have IB4 terminals in their vicinity. (c) Immunostaining with antibodies against p-S10H3 (red), CGRP (blue) and IB4 (purple). Dotted lines indicate the border between gray and white matter. D, dorsal; L, lateral. (d) Distribution of p-S10H3-immunoreactive nuclei within the CGRP- and IB4-positive bands and also in the deeper laminae of the SDH of rats and mice ( $\mathrm{n}=2$ animals per species). The CGRP band contains the vast majority of p-S10H3 nuclei in both species.

In accordance with Saeed and Ribeiro-da-Silva et al. [30], we observed that the density of the CGRP fibers was higher in the medial part of the superficial layers, than in the lateral regions of the spinal cord in a transverse section (Figure 2a1, and c). Interestingly, these authors reported that CGRP immunoreactivity was also detected in the inner region of lamina II in the rat [30]. Therefore, colocalization studies in this study were performed in a $100 \mu \mathrm{m}$ thick band measured from the surface of the superficial dorsal horn, where the majority of p-S10H3-expressing cells are surrounded by peptidergic CGRP fibers (Figure S1). However, as peptidergic CGRP fibers rarely extended as deep as $100 \mu \mathrm{m}$ into the grey matter of spinal cord, several p-S10H3-expressing cells fell outside the CGRP arborization territory (Figure S1). These outlier neurons, however, were clearly less abundant than their counterparts in the uppermost superficial layers (lamina I and Ilo; Figure S1). As in mice, p-S10H3-positive nuclei fall mostly within the CGRP-positive band of laminae I-IIo, while IB4 immunoreactivity fibers did not arborize $\mathrm{p}$-S10H3-containing neurons in the rat (Figure 2c,d). 


\subsection{S10H3 Phosphorylation Occurs Predominantly in SDH Neurons in Mice}

Quantitative analysis revealed that $83.5 \% \pm 8.9$ of p-S10H3-expressing cells were neurons based on their Fox-3 (NeuN)-positivity (total number of double-labeled cells: 523; total number of p-S10H3+ cells: 626), whereas p-S10H3-IR cells accounted for $17.1 \% \pm 3.7$ of the neurons labeled with NeuN in lamina I and IIo (total number of double-labeled cells: 523; total number of NeuN+ neurons: 3048; number of sections: 20 from six wild-type CD1 mice; Figure 3).
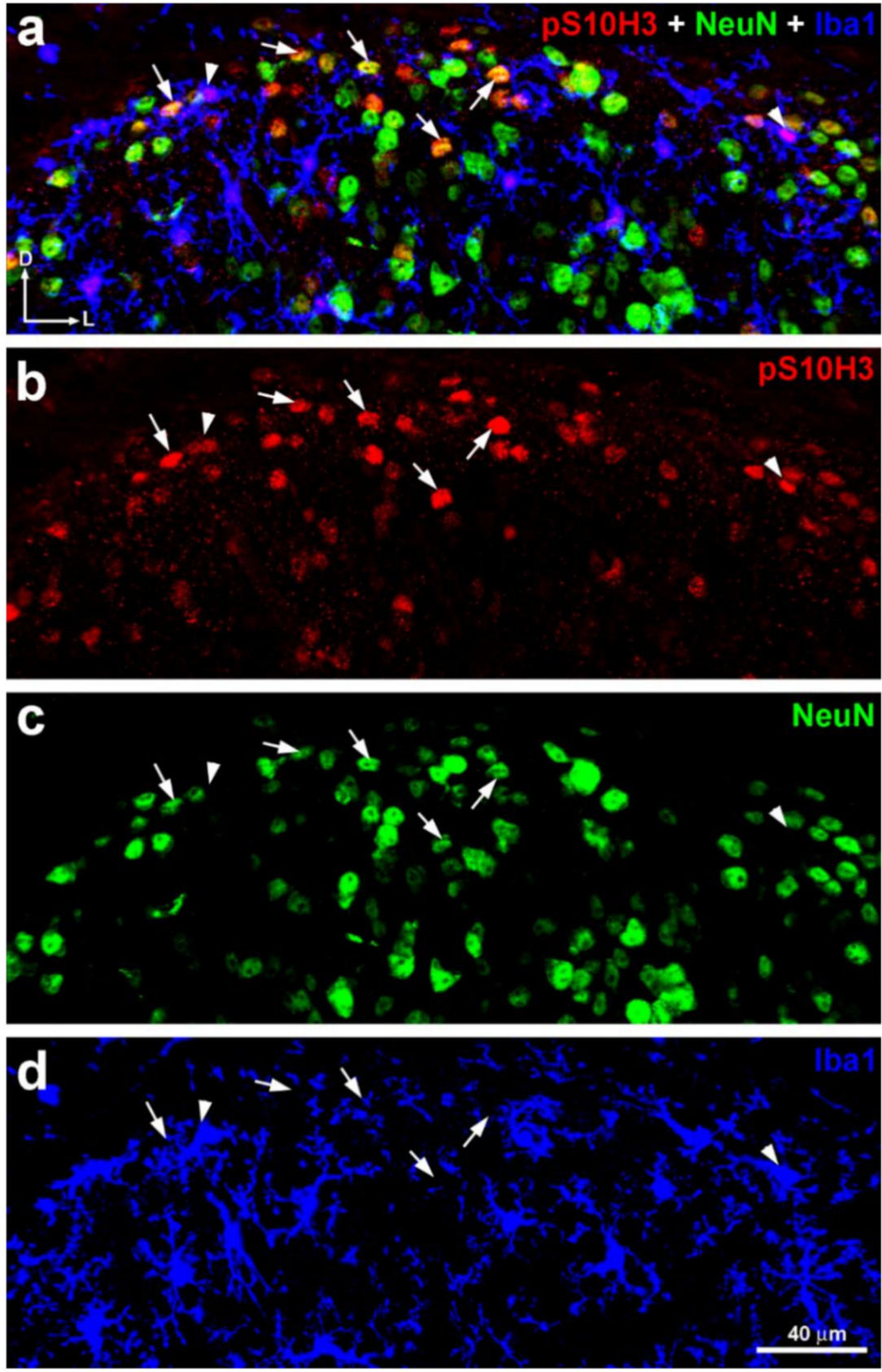

Figure 3. p-S10H3 was upregulated mainly but not exclusively in SDH neurons in mice after burn injury. (a-d) Immunostaining with antibodies against p-S10H3 (red; b), Fox-3 (NeuN) (green; c), and Iba-1 (blue; $\mathbf{d}$ ) in a transverse section of wild-type mouse. The merged image (a) clearly shows that almost all p-S10H3 positive nuclei are located in NeuN-positive somata (arrows) indicating that majority of them belong to neuronal population. Arrowheads label p-S10H3-expressing microglial cells. D, dorsal; L, lateral. 
The double immunolabeling of p-S10H3 with ionized calcium binding adaptor molecule 1 (Iba1) on another set of transverse spinal cord sections from wild-type mice revealed that Iba1-immunoreactive (IR) microglial cells that contained p-S10H3 in their nuclei were occasionally also visible in the superficial dorsal horn of the spinal cord $(3.5 \% \pm 0.8$; total number of double-labeled cells: eight; total number of p-S10H3 + cells: 224; number of section: nine from three mice; Figure 3), suggesting that the involvement of spinal microglial cells in the somatosensory processing of noxious heat-induced burn injury and consequential tissue damage is negligible, at least in the acute phase of burn injury.

\subsection{Only a Small Proportion of Projection Neurons Expresses Nuclear p-S10H3 Following Burn Injury}

Noxious information carried by primary afferents is modulated by local neuronal circuits in the SDH before being transmitted by PNs to higher brain areas $[14,15,31]$. Thus, we hypothesized that PNs, which receive monosynaptic primary afferent input from both nociceptive $C$ and $A \delta$ fibers [14,15,31,32], might be the main target cells for the earliest response to burn injury in which p-S10H3 is upregulated in burn injury.

Projection neurons were scattered along the whole rostrocaudal extent of the lumbar spinal cord after retrograde labeling with cholera toxin b-subunit $(\mathrm{CTb})$ from the lateral parabrachial nucleus $(\mathrm{LPb})$. The side of $\mathrm{CTb}$ injection (right $\mathrm{LPb}$ ) was contralateral to the side of burn injury (left hind leg). CTb-labeled neurons (i.e., PNs) were present in lamina I (Figure 4a), and also in the deeper layers (laminae III-IV; not shown) and were distributed bilaterally as expected [30], with the majority being contralateral to the side of the $\mathrm{CTb}$ injection (and ipsilateral to the noxious injury; Figure $4 \mathrm{~b}$ ). The average number of retrogradely labeled PNs was $39.7 \pm 8.3$ and $26.2 \pm 7.7$ on the ipsi- and contralateral sides (relative to the side of the burn injury), respectively (Figure $4 \mathrm{~b}, \mathrm{n}=17$ sections altogether from four rats). Three quarters of the CTb-labeled neurons on both sides $(74.8 \%$ and $75.2 \%$ ipsi- and contralaterally, respectively) showed immunoreactivity for the antibody against the NK1 receptor (NK1R; $29.7 \pm 8.2$ ipsilaterally; $19.7 \pm 5.9$ contralaterally) further confirming their identity as PNs. Burn injury-induced p-S10H3 nuclei were present in only $16.3 \%$ of laminae I and III-IV PNs ( $6.5 \pm 1.4$ PNs with $\mathrm{p}-\mathrm{S} 10 \mathrm{H} 3$ nuclei; $\mathrm{n}=17$ sections from four animals; Figure $4 b, c)$ and virtually all of these neurons also expressed NK1R (15.7\% of the total laminae I and III-IV PNs). Only approximately $5 \%$ of the total SDH neuronal population expressing nuclear p-S10H3 following burn injury proved to be PNs (Figure 4c), while of the PN population, 16\% contained p-S10H3 nuclei (Figure 4c).

\subsection{S10H3 Phosphorylation Occurs Predominantly in Local Interneurons in Mice}

Next, we wished to determine the SDH neuronal populations that show induced nuclear p-S10H3 upon burn injury. We selected characteristic markers that are abundant in excitatory and inhibitory SDH neuronal populations in laminae where the highest $\mathrm{p}-\mathrm{S} 10 \mathrm{H} 3$ expression was detected.

Pax-2 and Lmx1b are required for the gamma-amino butyric-acid (GABA)ergic and glutamatergic fates of spinal interneurons, respectively [6,8,33-37]. The double immunolabeling of p-S10H3 and Pax-2 in wild-type mice revealed that $24.0 \% \pm 5.0$ of p-S10H3-IR neurons was Pax-2 positive (36/150; $\mathrm{n}=6$ sections; Table 2; Figure $5 \mathrm{a}-\mathrm{c})$, while the double immunostaining of p-S10H3 and Lmx1b showed that 73.7\% $\pm 6.8(219 / 297 ; n=9$; Table 2; Figure $5 \mathrm{~d}-\mathrm{f}$ ) of p-S10H3-immunopositive neurons co-expressed Lmx1b suggesting that the larger proportion of $\mathrm{p}-\mathrm{S} 10 \mathrm{H} 3$-expressing neurons appears to be excitatory in function (Table 2; Figure 5). 

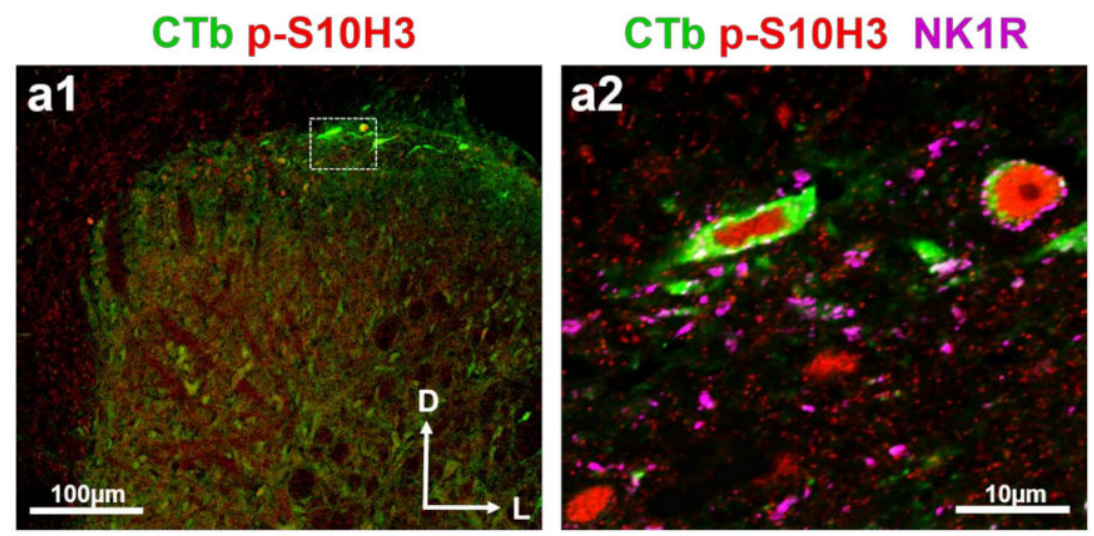

b

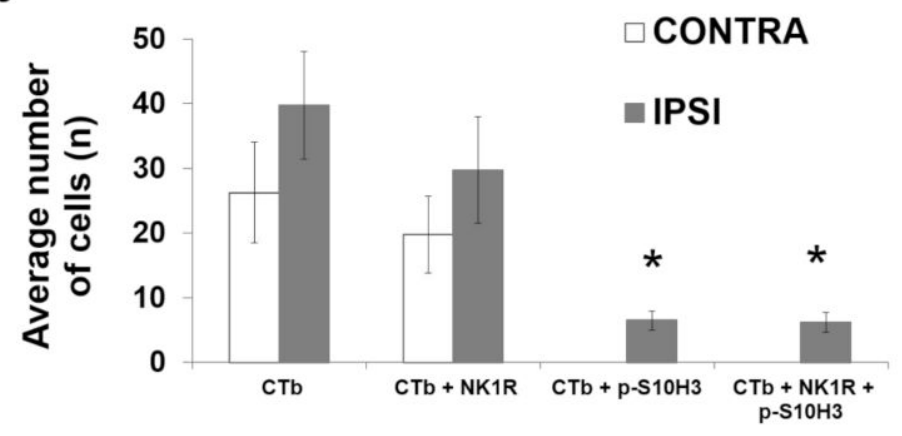

C

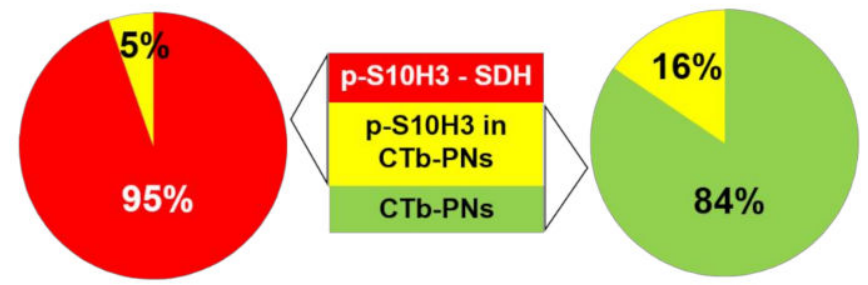

\section{CTb-PNs / p-S10H3 - SDH cells}

p-S10H3 / CTb-PNs

Figure 4. cholera toxin b-subunit $(\mathrm{CTb})$-labeled projection neurons rarely show nuclear burn injuryinduced p-S10H3. (a1,a2) Immunostaining with antibodies against p-S10H3 (red), CTb (green) and neurokinin-1 receptor (NK1) receptor (NK1R; magenta) in an L5 transverse spinal cord section of a rat after burn injury. (a2) Higher magnification image represents the region with two CTb-labeled projection neurons (PNs) outlined by dashed line in (a1). These two CTb/p-S10H3 co-labeled neurons express NK1R. (b) Average number of CTb-labeled projection neurons (PNs) containing p-S10H3 positive nuclei and NK1R immunoreactivity $(n=17,80-\mu$ m-thick sections per rat from 4 rats). IPSI refers to the side of the burn injury. Asterisks indicate a statistically significant difference between the ipsi- and contralateral sides of $\mathrm{SDH}\left({ }^{*} p<0.05\right)$. Note that the numbers of CTb-PNs with p-S10H3 or $\mathrm{CTb} / \mathrm{p}-\mathrm{S} 10 \mathrm{H} 3 / \mathrm{NK} 1 \mathrm{R}$ ipsilaterally are negligible. Note also that the CTb-PNs could be detected on both sides. (c) Percentage of CTb-PNs within the total p-S10H3 positive SDH cell population (left) and percentage of PNs with $\mathrm{p}-\mathrm{S} 10 \mathrm{H} 3$ positive nuclei within the total $\mathrm{CTb}$ labeled PN population in the SDH (right). 
Table 2. Percentage of $\mathrm{p}-\mathrm{S} 10 \mathrm{H} 3+$ neurons after burn injury that were Pax-2 or Lmx1b-immunoreactive (IR) in wild type mice or that were VGAT- or vesicular glutamate transporter 2 (Vglut2)-IR in VGATor Vglut2:tdTomato transgenic mice.

\begin{tabular}{cccccc}
\hline & p-S10H3 $^{\#}$ & IR $^{\# \#}$ & Double $^{\# \#}$ & Double/p-S10H3 & Double/IR \\
\hline $\begin{array}{c}\text { Pax-2 } \\
(\mathrm{n}=6)\end{array}$ & 150 & 198 & 36 & $24.00 \%$ & $18.10 \%$ \\
$\begin{array}{c}\text { Lmx1b } \\
(\mathrm{n}=9)\end{array}$ & 297 & 711 & 219 & $73.70 \%$ & $30.80 \%$ \\
$\begin{array}{c}\text { VGAT } \\
(\mathrm{n}=16)\end{array}$ & 420 & 538 & 67 & $15.90 \%$ & $12.40 \%$ \\
$\begin{array}{c}\text { Vglut2 } \\
(\mathrm{n}=16)\end{array}$ & 287 & 831 & 128 & $44.50 \%$ & $15.40 \%$
\end{tabular}

\# total number of cells with p-S10H3-nuclei 5 min after burn injury counted in lamina I and IIo. \#\# total number of cells immunoreactive (IR) for the given cell type specific marker counted in lamina I and IIo. \#\#\# total number of cells immunoreactive for the given marker showing p-S10H3 in their nuclei counted in lamina I and IIo. Number of sections (from 3 wild-type CD1 mice; two VGAT:tdTomato or 3 Vglut2:tdTomato transgenic mice) is shown in brackets. Values in the last column indicate \% of p-S10H3-positive neurons that colocalized with the given marker.

To further confirm our results, we applied yet another strategy and used anti-red fluorescent protein (RFP) antibody against tdTomato on lumbar spinal cord sections from vesicular gamma-amino butyric-acid (GABA) transporter (VGAT)- and vesicular glutamate transporter 2 (Vglut2):tdTomato mice, to determine the proportion of inhibitory and excitatory subsets of $\mathrm{p}-\mathrm{S} 10 \mathrm{H} 3$-expressing $\mathrm{SDH}$ neurons. The Vglut2 was selected as an excitatory marker, since virtually all spinal excitatory neurons express Vglut2 [38]. Inhibitory neurons were identified based on the presence of the VGAT, which is crucial for the loading and storage of GABA, as well as glycine in synaptic vesicles, and localizes exclusively in inhibitory axon terminals [39]. In this set of experiments, we found that only $15.9 \% \pm 4.6$ (67 out of 420; number of sections: 16 from two mice) of the total number of burn injury-induced p-S10H3 nuclei were confined within VGAT-positive neurons (Table 2; Figure 5g-i), while near half (44.5\% $\pm 8.5 ; 128$ out of 287; number of section: 16 from three animals) of them were located in glutamatergic neuronal somata as assessed by the expression of tdTomato in Vglut2:tdTomato mice (Table 2; Figure 5j-1). Note that the Vglut2 + VGAT population together does cover around two thirds of the neurons with burn injury-induced nuclear p-S10H3 expression.

From these results, it appears that $\mathrm{p}-\mathrm{S} 10 \mathrm{H} 3$ upregulation in burn injury occurs in various types of interneurons, the majority of which are indeed excitatory.

2.6. Burn Injury-Induced S10H3 Phosphorylation Occurs Mainly in a Dynorphinergic Population of SDH Neurons in Mice

Since the majority of SDH neurons expressing p-S10H3 proved to be glutamatergic and near one fifth were GABAergic, we carried out double immunostaining for different neurochemical markers of both inhibitory and excitatory neuronal populations to determine their proportion in the subset of SDH cells responding to burn injury with nuclear p-S10H3 expression.

Among the well-defined excitatory interneurons, only somatostatin (SOM), substance $\mathrm{P}(\mathrm{SP})$ and GRP-positive cells are located in the superficial laminae $[18,21,22,40,41]$ where p-S10H3 neurons are concentrated upon burn injury. Therefore, we examined the colocalization of these markers with p-S10H3 after burn injury. According to the literature $[5,8,18,21]$, SOM-expressing cells account for $\sim 60 \%$ of excitatory interneurons in the superficial dorsal horn and exhibit rather heterogenous populations expressing additional types of neuropeptides. In our experiments, the double labeling of $\mathrm{p}-\mathrm{S} 10 \mathrm{H} 3$ and $\mathrm{SOM}$ revealed that $60.2 \% \pm 15$ (47 out of 78; Figure 6a1-a3; Table 3) of p-S10H3-IR cells was SOM+, while $32.1 \% \pm 5.9$ of SOM-IR neurons expressed p-S10H3 (47 out of 146; data not shown). 

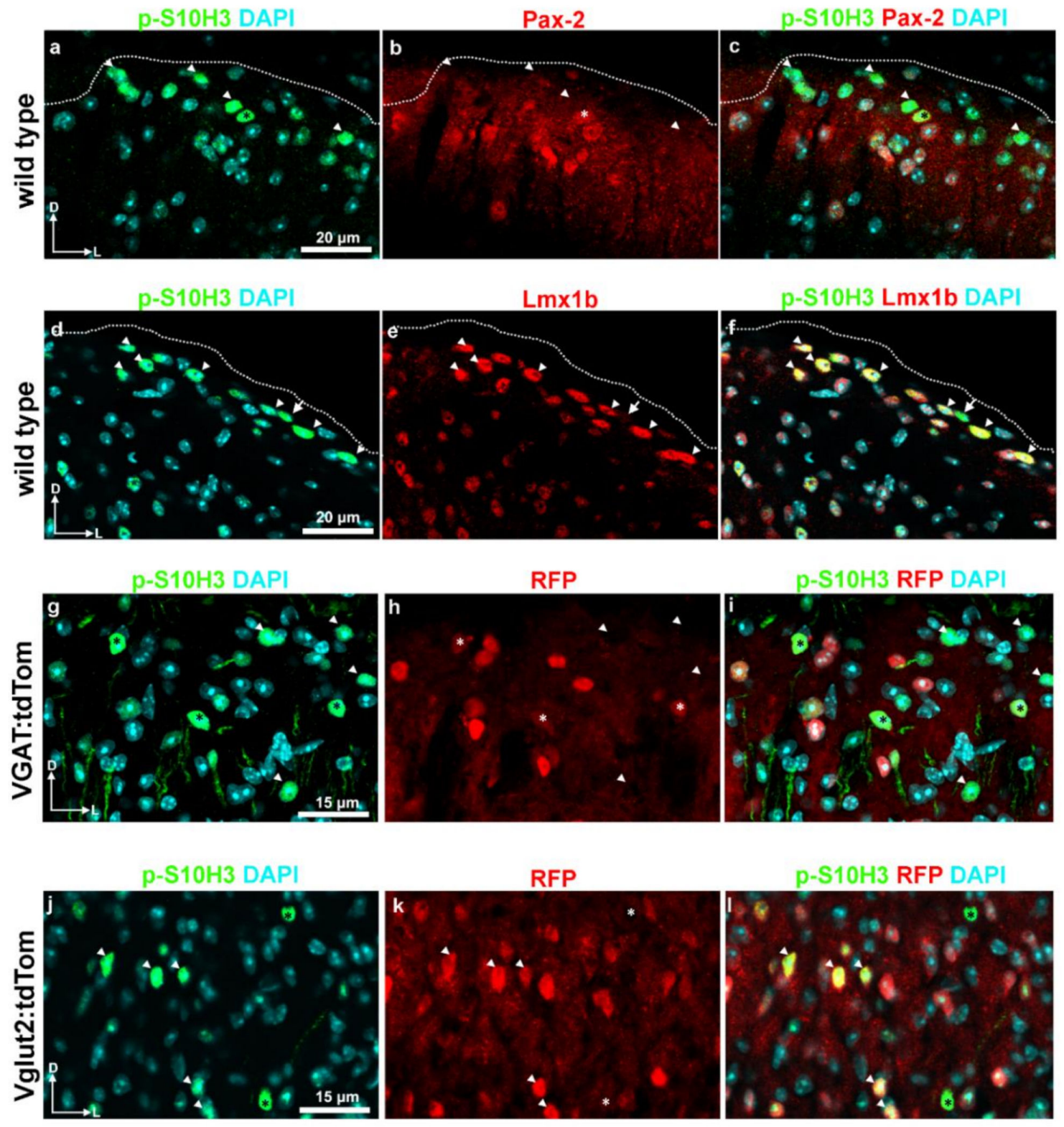

Figure 5. p-S10H3 is upregulated predominantly in excitatory interneurons both in wild-type and transgenic mice after burn injury. (a-c) Immunostaining with antibodies against p-S10H3 (green) and Pax-2 (red) in a transverse section of a wild-type mouse. In this field of view, there is only one Pax-2-positive neuron that exhibits p-S10H3-IR in its nucleus (asterisk). Arrowheads mark p-S10H3-IR neurons which lack Pax-2. (d-f) Immunostaining with antibodies against p-S10H3 (green) and Lmx1b (red) in a transverse section of a wild-type mouse. In this field of view, there are numerous p-S10H3-positive neurons co-labeled with Lmx1b (arrowheads), while there is only one p-S10H3-IR cell that lacks Lmx1b (arrow). The dotted line indicates the border between gray and white matter $(\mathbf{a}-\mathbf{f}) .(\mathbf{g}-\mathbf{i})$ Immunostaining with antibodies against p-S10H3 (green) and red fluorescent protein (RFP) (red; against to tdTomato) in a transverse section of a vesicular gamma-amino butyric-acid (GABA) transporter (VGAT):tdTomato transgenic animal. There are three p-S10H3-positive neurons that exhibit weak RFP labeling in their cytoplasm (asterisks). Several p-S10H3-IR neurons without RFP-labeling can also be visible (arrowheads). (j-1) Immunostaining with antibodies against p-S10H3 (green) and RFP (red; against to tdTomato) in a transverse section of a Vglut2:tdTomato transgenic animal. Nearly half of the p-S10H3-positive nuclei are located in tdTomato-positive somata (arrowheads), indicating their glutamatergic nature. There are additionally two p-S10H3-expressing neurons that lack RFP signals (marked with asterisks). D, dorsal; L, lateral. 

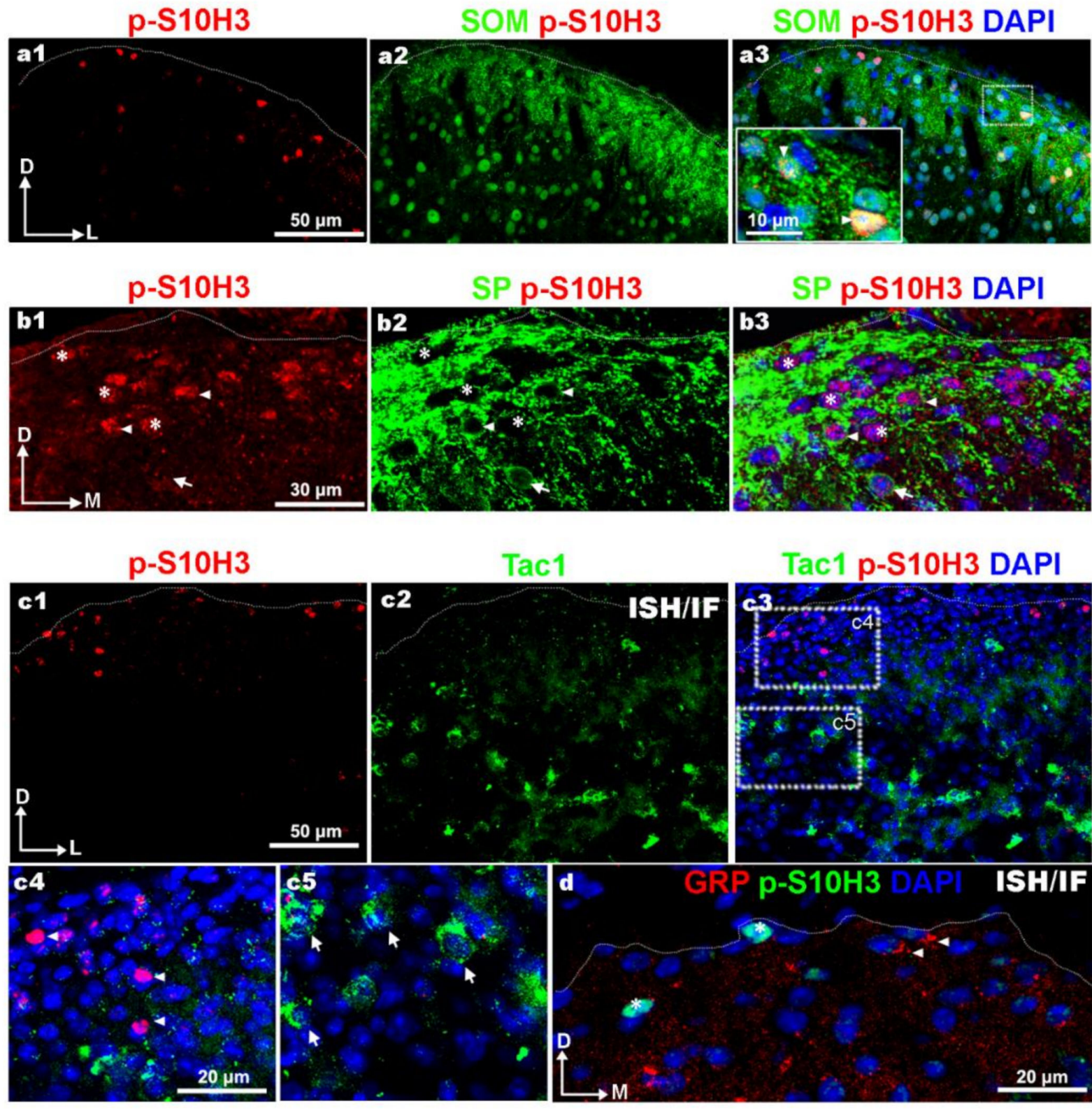

Tac1

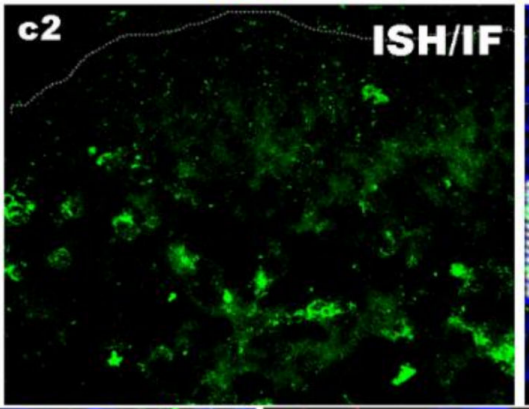

Tac1 p-S10H3 DAPI
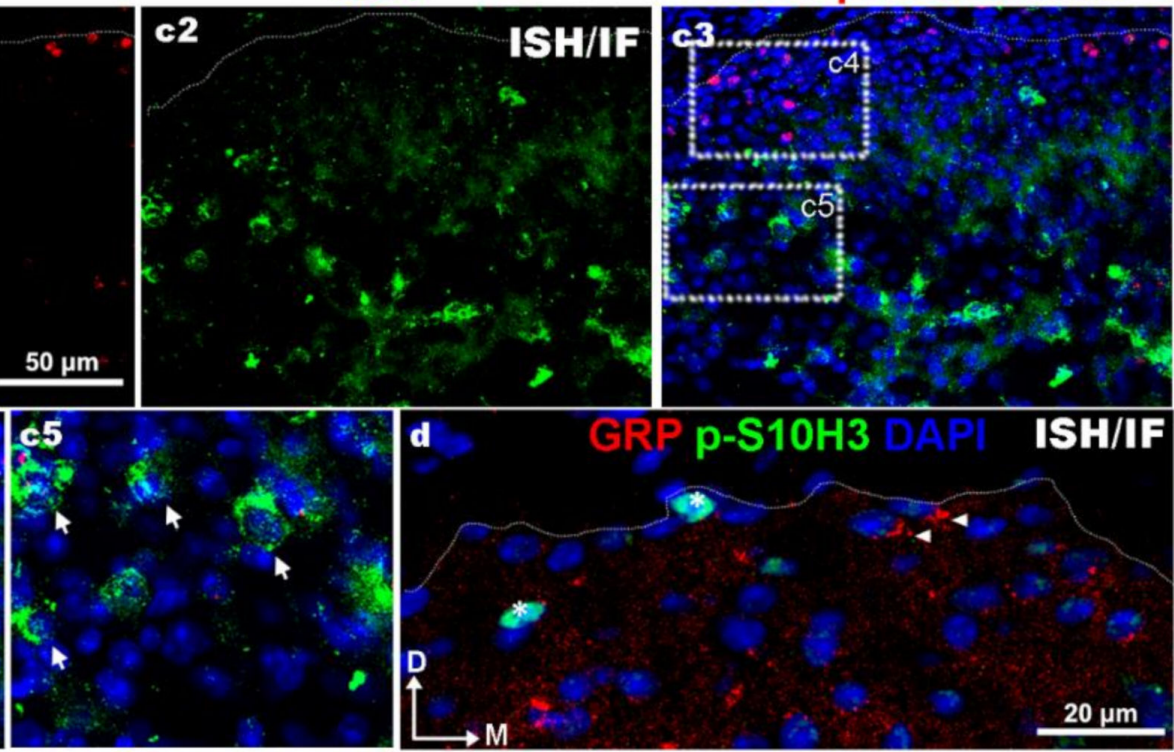

ISH/IF

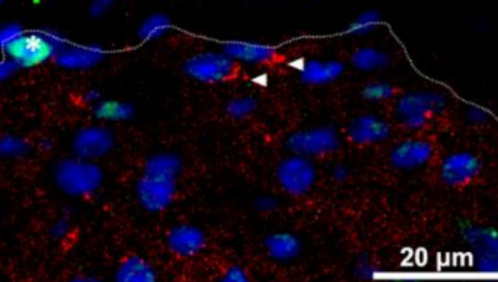

Figure 6. Burn injury-induced $\mathrm{S} 10 \mathrm{H} 3$ phosphorylation in excitatory subpopulations of SDH neurons. (a1-a3) A representative image showing immunostaining for $\mathrm{p}-\mathrm{S} 10 \mathrm{H} 3$ (red; a1,a3) and somatostatin (SOM; green; a2,a3) in a transverse section of wild-type mouse. (a3) shows a merged image with 4',6-diamidino-2-phenylindole (DAPI) (blue). In the inset there are two p-S10H3-positive neurons that exhibit strong SOM labeling in their cytoplasm (arrowheads). (b1-b3) A representative image showing immunostaining for $\mathrm{p}-\mathrm{S} 10 \mathrm{H} 3$ (red; $\mathbf{b} 1, \mathbf{b} 3)$ and substance $\mathrm{P}(\mathrm{SP} ;$ green; b2,b3) in a transverse section of wild-type mouse. (b3) shows a merged image with DAPI (blue). There are some SP-containing neuronal soma with (arrowheads) or without p-S10H3 (arrow) in their nuclei. Asterisks show p-S10H3-IR neurons that probably do not produce SP. (c1-c5) A representative image showing immunostaining for p-S10H3 (red; c1,c3) and in situ hybridization (ISH) signal for Tac1 mRNA (green; c2,c3). (c3) shows a merged image with DAPI (blue). Insets represent higher magnification views of regions of interest designated on image (c3). Arrowheads label p-S10H3-IR neurons that probably do not produce substance P due to its low level of Tac1 mRNA (c4). Arrows indicates Tac1 mRNA containing cell bodies that do not show p-S10H3-IR (c5). (d) Immunostaining for p-S10H3 (green), cell nuclei specific DAPI (blue) and ISH signal for GRP mRNA (red). Interestingly, SDH neurons containing GRP mRNA (arrowheads) never express pS10H3-positive nuclei (asterisks) following burn injury. The dotted line indicates the border between gray and white matter $(\mathbf{a}-\mathbf{d})$. D, dorsal; L, lateral; M, medial. 
Table 3. Proportion of p-S10H3 nuclei after burn injury in different subsets of neurons defined by their neurochemical phenotypes in laminae I and IIo. nNOS: neuronal nitrogen monoxide synthase.

\begin{tabular}{cccccc}
\hline & p-S10H3 $^{\#}$ & IR $^{\# \#}$ & Double ${ }^{\# \#}$ & Double/p-S10H3 & Double/IR \\
\hline $\begin{array}{c}\text { somatostatin } \\
(\mathrm{n}=3)\end{array}$ & 78 & 146 & 47 & $60.20 \%$ & $32.10 \%$ \\
$\begin{array}{c}\text { Dynorphin } \\
(\mathrm{n}=7)\end{array}$ & 277 & 151 & 95 & $34.20 \%$ & $62.90 \%$ \\
$\begin{array}{c}\text { Dynorphin } \\
(\mathrm{n}=10)\end{array}$ & 202 & 186 & 78 & $38.60 \%$ & $41.90 \%$ \\
$\begin{array}{c}\text { calretinin } \\
(\mathrm{n}=11)\end{array}$ & 385 & 253 & 33 & $8.30 \%$ & $12.60 \%$ \\
$\begin{array}{c}\text { nNOS } \\
(\mathrm{n}=7)\end{array}$ & 248 & 72 & 8 & $3.20 \%$ & $11.10 \%$ \\
$\begin{array}{c}\text { NPY } \\
(\mathrm{n}=5)\end{array}$ & 154 & 6 & 1 & $0.60 \%$ & $16.60 \%$ \\
$\begin{array}{c}\text { parvalbumin } \\
(\mathrm{n}=3)\end{array}$ & 93 & 36 & 2 & $2.10 \%$ & $5.50 \%$ \\
\hline
\end{tabular}

\# total number of neurons with p-S10H3-nuclei 5 min after burn injury. "\# total number of neurons immunoreactive (IR) for the given neurochemical marker. ${ }^{\# \#}$ total number of neurons immunoreactive for the given neurochemical marker showing p-S10H3 in their nuclei. * values from wild-type CD1 mice $(\mathrm{n}=3) .{ }^{\$}$ values from Pdyn:EGFP transgenic mice $(n=2)$ in which dynorphinergic neurons express EGFP cre-dependently. Number of sections (from 3 CD1 mice; otherwise indicated) is shown in brackets. Values in the last column indicate \% of p-S10H3-positive neurons that colocalized with the given neurochemical marker.

Consistent with the findings that only $20 \%$ of the SP content of the dorsal horn is produced by local excitatory interneurons, SP-IR perikarya were fairly seldom encountered in laminae I-II, with abundant axonal arborization (Figure 6b1-b3). The most intense staining for Tac1 mRNA was detected in neurons located outside the most superficial laminae, where very few $\mathrm{p}$-S10H3-containing nuclei were observed and therefore there was virtually no overlap between Tac1 mRNA and p-S10H3 protein (Figure 6(c1-c5)). GRP-IR neurons could not be identified with certainty due to the fact that GRP protein level in their cell bodies was below the threshold for detection with immunostaining (data not shown) as also confirmed by Barry et al. [41]. We have only detected very weak perikaryal staining in our immunofluorescent staining for substance P and GRP, despite trying several antibodies from different companies, and if anything, those neurons have been covered by the large amounts of primary afferents terminals in the most superficial laminae. Therefore, substance P and GRP-producing neuronal cell bodies were identified with riboprobes directed against Tac1 (encodes SP) and GRP mRNAs in in situ hybridization (ISH) experiments combined with immunostaining for p-S10H3 (Figure $6 \mathrm{c} 1-\mathrm{c} 5$ and d). The most intense staining for Tac1 mRNA was detected in neurons located in laminae II-III and also scattered evenly in the deeper dorsal horn (Figure 6c1-c5), and therefore there was virtually no overlap with p-S10H3 (Figure 6c1-c5). SDH neurons containing GRP mRNA never expressed pS10H3 following burn injury (Figure 6d).

Next, we selected five markers previously associated with inhibitory SDH neurons [42]: parvalbumin (PV), calretinin (CR), neuropeptide Y (NPY), neuronal nitrogen monoxide synthase (nNOS) and prodynorphin (Pdyn). Sections from wild-type mice were reacted with p-S10H3, one of the above listed inhibitory markers and the neuronal cell body-specific NeuN to reveal the distribution of the p-S10H3-expressing neurons among the inhibitory SDH neuronal populations. Due to species incompatibility in the cases of calretinin and parvalbumin, NeuroTrace fluorescent Nissl stain (Nissl) was applied instead of NeuN (Table 4). Representative images of sections derived from wild-type mice immunostained for these inhibitory markers are shown in Figure 7, while quantitative analysis of the proportions of markers in neurons with p-S10H3 nuclei is summarized in Table 3. Neurons in laminae I-IIo expressing p-S10H3 upon burn injury showed the highest co-expression $(34.2 \% \pm 3.3 ; 95 / 277 ; \mathrm{n}=7$ sections from three wild-type mice) with prodynorphin and $62.9 \% \pm 3.3$ of the Pdyn-IR neurons expressed nuclear p-S10H3 (95/151; $\mathrm{n}=7$ sections from 
three wild-type mice; Figure 7e1-e3). To improve the detection of dynorphinergic somata, we repeated the quantification on sections from Pdyn:enhanced green fluorescent protein (EGFP) transgenic hybrid mice. We have previously validated this hybrid and showed that over $90 \%$ of EGFP+ cells in sections from Pdyn:EGFP mice were Pdyn-IR neurons (Figure S2). In these sections, 38.6\% $\pm 4.3(78 / 202 ; n=10$ sections from three animals) of p-S10H3-immunoreactive nuclei belonged to dynorphinergic neurons, which is consistent with the data obtained above in wild-type animals.

Table 4. Details of primary antibodies used for immunofluorescent staining.

\begin{tabular}{|c|c|c|c|c|}
\hline Name & Species & Dilution & Supplier & Cat. No. \\
\hline p-S10H3 & rabbit & $1: 600$ & Abcam (Cambridge, UK) & ab5176 \\
\hline $\mathrm{p}-\mathrm{S} 10 \mathrm{H} 3$ & mouse & 1:1000 & Abcam (Cambridge, UK) & ab14955 \\
\hline GFP & chicken & $1: 2000$ & Abcam (Cambridge, UK) & ab13970 \\
\hline RFP & rat & 1:1000 & Chromotec (Planegg-Martinsried, Germany) & $5 f 8-100$ \\
\hline Choleratoxin B & goat & 1:2000 & List Biol Labs (Campbell, CA, USA) & 703 \\
\hline NK1R & guinea pig & $1: 25000$ & Merck, KGaA (Darmstadt, Germany) & AB15810 \\
\hline IBA-1 & guinea pig & $1: 500$ & SYSY (Göttingen, Germany) & 234004 \\
\hline \multicolumn{2}{|c|}{$\begin{array}{c}\text { NeuroTrace } \\
500 / 525 \text { Nissl }\end{array}$} & 1:1000 & Thermo Fisher Sci. Inc. (Waltham, MA, USA) & N21480 \\
\hline CGRP & guinea pig & $1: 5000$ & Peninsula (San Carlos, CA, USA) & $\mathrm{T}-5027$ \\
\hline Isolectin IB4 * & & $1: 5000$ & Thermo Fisher Sci. Inc. (Waltham, MA, USA) & $\mathrm{I} 21414$ \\
\hline NeuN & mouse & 1:1000 & Millipore (Burlington, MA, USA) & MAB377 \\
\hline calretinin & mouse & 1:6000 & Swant (Marly, Switzerland) & 6B3 \\
\hline parvalbumin & mouse & 1:2000 & Swant (Marly, Switzerland) & PV235 \\
\hline neuropeptid $Y$ & guinea pig & $1: 600$ & Novus Biol (Centennial, CO, USA) & NB100-1624 \\
\hline nNOS & goat & $1: 1000$ & Novus Biol (Centennial, CO, USA) & NB100-858 \\
\hline somatostatin & rabbit & $1: 200$ & GeneTex (Irvine, CA, USA) & GTX133119 \\
\hline substance $\mathrm{P}$ & rat & $1: 100$ & Santa Cruz (Dallas, TX, USA) & sc-21715 \\
\hline Pax-2 & rabbit & $1: 400$ & Thermo Fisher Sci. Inc. (Waltham, MA, USA) & $71-6000$ \\
\hline Lmx1b & rabbit & $1: 400$ & Abcam (Cambridge, UK) & ab66941 \\
\hline prodynorphin & guinea pig & $1: 600$ & GeneTex (Irvine, CA, USA) & GTX10280 \\
\hline
\end{tabular}

* IB4, biotin-conjugated and visualized by fluorescent-streptavidin (1:1000, Thermo Fisher Sci. Inc. (Waltham, MA, USA)).

In accordance with Boyle et al. [42], the great majority of dynorphin-expressing cells in laminae I-IIo also expressed galanin ( $89.1 \%$; 90 out of 101$)$, whereas only $57.3 \%$ of the galanin-expressing cells co-labeled with dynorphin (90 out of 157; 7 sections from two mice; data not shown). The other notable subpopulation of SDH cells that expressed nuclear p-S10H3 was that of calretinin neurons $(8.3 \% \pm 2.3)$, whereas $12.6 \% \pm 1.7$ of calretinin-expressing cells showed p-S10H3-IR (Figure 7b1-b3 and Table 3). The proportion of $\mathrm{p}-\mathrm{S} 10 \mathrm{H} 3+/ \mathrm{CR}+$ double-labeled neurons that were inhibitory and excitatory were $36 \% \pm 1.4$ and $75 \% \pm 2.6$, respectively, based on their co-labeling with tdTomatospecific anti-RFP in VGAT- or Vglut2:tdTomato mice (Table S1). The other three inhibitory markers (parvalbumin, NPY, nNOS) showed very limited overlap, if any, with p-S10H3 (Figure 7a1-a3, c1-c3, d1-d3; see in Table 3). However, the SDH region where p-S10H3 nuclei were concentrated showed a high density of NPY-positive processes and bouton-like profiles (Figure 7c1-c3). 


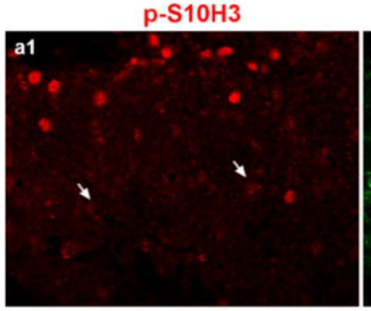

p-S10H3

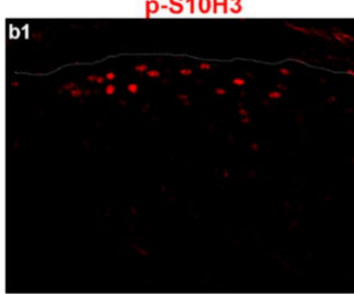

p-S10H3

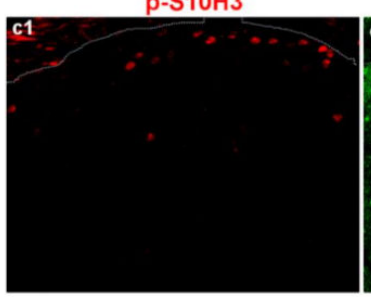

$\mathrm{p}-\mathrm{S} 10 \mathrm{H} 3$

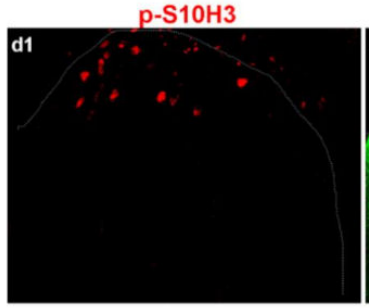

p-S10H3

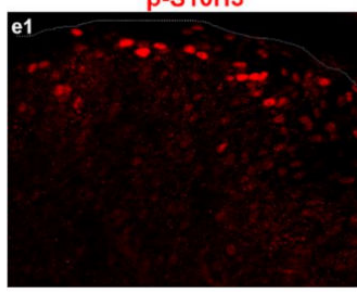

paryalbumin

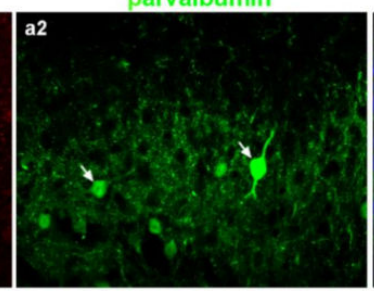

calretinin

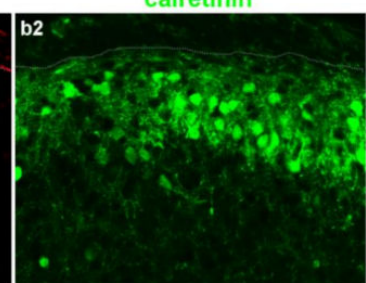

NPY

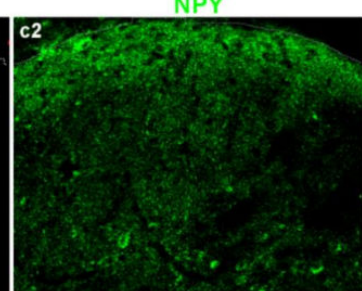

nNOS

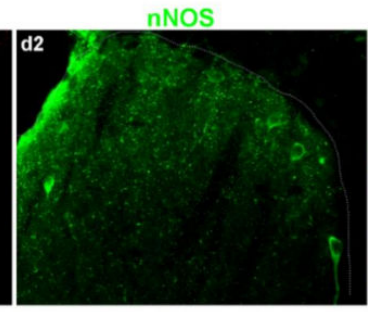

Pdyn

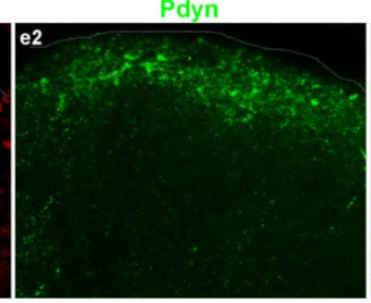

Nissl p-S10H3 parvalbumin

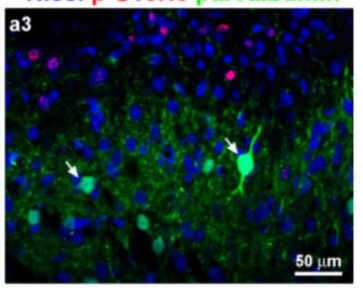

Nissl p-S10H3 calretinin

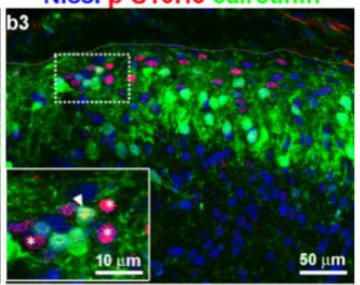

NeuN p-S10H3 NPY

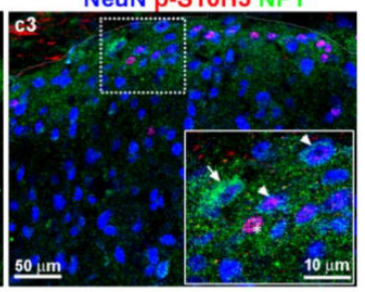

NeuN p-S10H3 nNOS

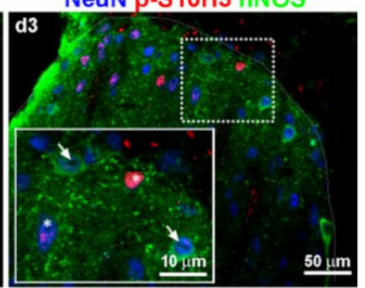

NeuN p-S10H3 Pdyn

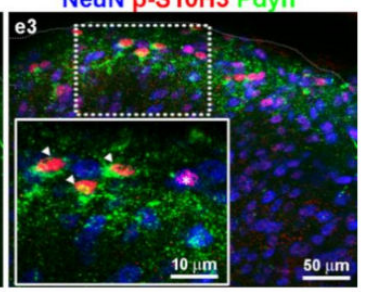

Figure 7. Burn injury-induced $\mathrm{S} 10 \mathrm{H} 3$ phosphorylation in inhibitory subpopulations of SDH neurons. (a1-a3) A representative image showing immunostaining for p-S10H3 (red; a1,a3), Nissl dye (blue; a3) and parvalbumin (green; a2-a3). Nearly all p-S10H3-positive nuclei fell outside the band rich in parvalbumin-immunoreactive profiles and none was present in parvalbumin positive somata of deeper laminae (arrows). (b1-b3) Immunostaining for p-S10H3 (red; b1,b3), Nissl dye (blue; b3) and calretinin (green; b2,b3). Calretinin positive neurons occasionally contained p-S10H3-positive nuclei (arrowhead in the inset). Asterisks indicate p-S10H3-IR neurons without calretinin immunolabeling. (c1-c3) Immunostaining for p-S10H3 (red; c1,c3), neuronal marker, NeuN (blue; c3) and NPY (green; c2,c3). Hardly any of the rare NPY-IR neuronal somata contained a p-S10H3-positive nucleus as indicated with arrowheads. Asterisk marks p-S10H3-IR neurons without NPY immunolabeling. Arrow marks an NPY+ interneuron that lacks p-S10H3. (d1-d3) Immunostaining with antibodies against p-S10H3 (red; d1,d3), NeuN (blue; d3) and nNOS (green; d2,d3). Asterisk indicates a p-S10H3-IR neuron without nNOS immunolabeling. Arrows show nNOS-IR neurons in which p-S10H3 was not upregulated upon burn injury. (e1-e3) Immunostaining with antibodies against p-S10H3 (red; e1,e3), NeuN (blue; e3) and prodynorphin (Pdyn) (green; e2,e3). Several p-S10H3-immunostained nuclei were localized within dynorphin-positive somata (arrowheads in the inset). In the higher magnification image, an asterisk labels a non-dynorphinergic neuron that exhibits $\mathrm{p}-\mathrm{S} 10 \mathrm{H} 3$. Dotted lines indicate the border between gray and white matter $(\mathbf{b} 3, \mathrm{c} 3, \mathrm{~d} 3, \mathrm{e} 3)$. 
Taken together, these results indicate that $\mathrm{p}-\mathrm{S} 10 \mathrm{H} 3$-expressing nuclei mostly belong to $\mathrm{SOM}+$ and Pdyn+ cells. As stated above, SOM+ neurons exhibit rather diverse populations expressing various types of additional neuropeptides including Pdyn $[5,8,18,21]$. While our own observation that $23.3 \%$ of p-S10H3+/Pdyn+ double-labeled neurons (5 out of 21 in three sections) was SOM+ in Pdyn:EGFP mice (unpublished data) supports this, we focused our interest on the distinct population of Pdyn+ neurons that showed p-S10H3 upregulation following burn injury-induced tissue damage and did not try to separate the SOM/Pdyn double positive group.

\subsection{The Highest Proportion of p-S10H3 Nuclei Appears in Excitatory Dynorphinergic Neurons Following Burn Injury}

The above experiments confirmed that the majority of the p-S10H3-expressing neuronal population belonged to an excitatory pool of interneurons as p-S10H3 upregulation caused by noxious heat-induced burn injury and tissue damage occurred to a greater extent in Lmx1b-IR SDH neurons (73.7\%; see Table 2). While dynorphinergic neurons are mainly GABAergic, excitatory interneurons have also been demonstrated to express Pdyn in the mouse [42-44], thus we wanted to check if Pdyn neurons expressing p-S10H3 after burn injury belong to the excitatory group.

To address this issue, we determined the proportion of p-S10H3-expressing Pdyn neurons that were immunoreactive to Pax-2 and Lmx1b on sections from Pdyn:EGFP mice ( $\mathrm{n}=3$ animals; Figure 8$)$. As expected, we found that only $22.2 \% \pm 3.3$ of $\mathrm{p}-\mathrm{S} 10 \mathrm{H} 3-$ expressing dynorphinergic neurons (10/45; Figure 8a) were Pax-2-positive, while the majority of them (83.3\%; 30/36; Figure 8b) had Lmx1b-IR in laminae I-IIo following burn injury. The proportion of p-S10H3-expressing Pdyn+ cells with Lmx1b-IR was significantly higher than the proportion of $\mathrm{p}-\mathrm{S} 10 \mathrm{H} 3$-expressing Pdyn+ neurons with Pax-2-IR ( $p=0.026$; 3-6 sections from three mice).

Using an alternative strategy, of p-S10H3+/Pdyn+ double-labeled neurons, 20.4\% \pm 6.4 ( 10 out of $49 ; n=6$ ) were inhibitory and $47.2 \% \pm 13.3$ ( 34 out of $72 ; n=7$ ) were excitatory based on their co-labeling with tdTomato-specific anti-RFP signals in VGAT- or Vglut2:tdTomato mice (Table S1). This result was consistent with our previous findings obtained with Pax-2 and Lmx1b antibodies, although the proportion of excitatory p-S10H3expressing Pdyn-IR cells based on findings in the Vglut2:tdTomato mice appears to be underestimated as compared to the value calculated by Lmx1b positivity.

In summary, these results strongly suggest that the excitatory, rather than inhibitory subset of dynorphinergic neurons contributes to nociceptive processing mediated via p-S10H3 upregulation following noxious heat. 

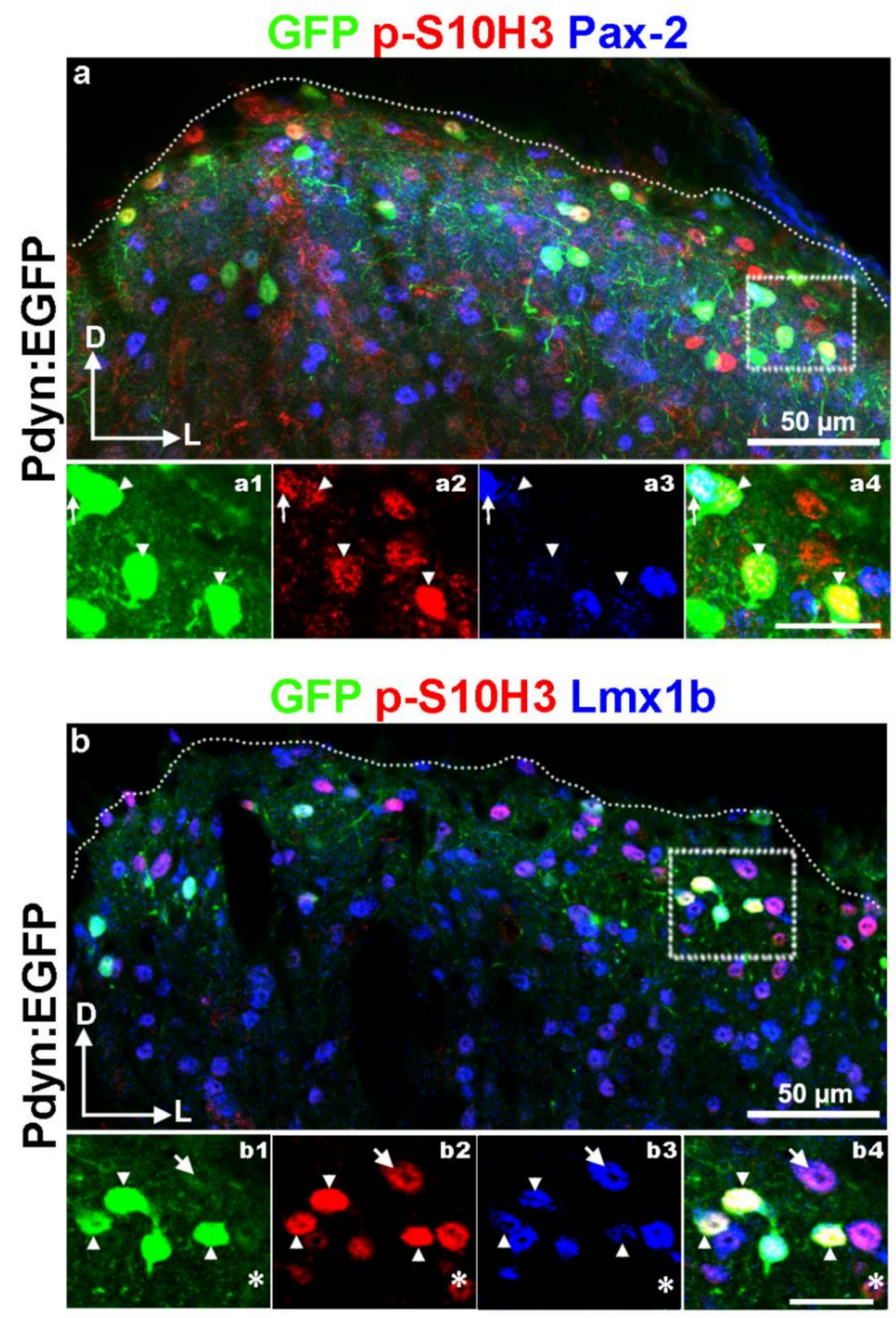

Figure 8. Burn injury-induced $\mathrm{p}-\mathrm{S} 10 \mathrm{H} 3$ nuclei are dominantly expressed by the excitatory subpopulation of dynorphinergic SDH neurons. (a) A representative image showing immunostaining for p-S10H3 (red), GFP (green) and Pax-2 (blue) in a transverse spinal cord section of Pdyn:enhanced green fluorescent protein (EGFP) mouse. In the inset (a1-a4) there are several anti-GFP antibodylabeled dynorphinergic neurons. Of these, there is only one p-S10H3-expressing Pdyn+ neuron that exhibits Pax-2-IR (labeled with an arrow), while the others lack Pax-2 (arrowheads; a1-a4). (b) A representative image showing immunostaining for p-S10H3 (red), GFP (green) and Lmx1b (blue) in a transverse spinal cord section of Pdyn:EGFP mouse. In the insets (b1-b4), numerous p-S10H3-immunoreactive nuclei are visible in laminae I-IIo of the SDH. Of these, the majority express Lmx1b and thus presumably they are excitatory. While there are several p-S10H3+/Lmx1b+ neurons that proved to be dynorphinergic based on their strong cytoplasmic GFP-staining (arrowheads in the insets), there is only one that is non-dynorphinergic (indicated by an arrow). The asterisk indicates such a p-S10H3-IR neuron that is immunonegative both for Lmx1b and Pdyn. The dotted line represents the border between gray and white matter $(\mathbf{a}, \mathbf{b})$. D, dorsal; L, lateral. Scale bars in the insets are $20 \mu \mathrm{m}$.

\section{Discussion}

Transcriptional and translational modifications in SDH neurons are pivotal in the development and maintenance of long-term pain conditions. Activity- and stimulus- 
dependent changes in gene expression regulated by epigenetic mechanisms (e.g., acetylation, phosphorylation, methylation, ubiquitylation, etc., of histone proteins) lead to alterations in neuronal activity $[1,2,45,46]$. The significance of histone $3(\mathrm{H} 3)$ acetylation in the maintenance of pathological pain conditions has already been emphasized in previous studies [2,47]. Histone $\mathrm{H} 3$ phosphorylation at serine 10 in the spinal cord, however, has only gained attention recently as a potential player in nociceptive sensitization in several animal models of inflammatory pain [3,4], achieving this by a cell-type dependent permissive transcriptional program in post-mitotic neurons $[3,46,48]$. Superficial dorsal horn (SDH) neurons participating in pain processing, however, show considerable heterogeneity $[16,49]$, thus our goal was to determine the segmental distribution of p-S10H3 in the lumbar segments of spinal cord in the mouse and also to identify subpopulations of SDH neurons that express $\mathrm{p}-\mathrm{S} 10 \mathrm{H} 3$ and also following noxious thermal stimulation.

Several technical considerations must be highlighted first. Noxious stimuli $\left(60^{\circ} \mathrm{C}\right.$; capsaicin or formalin), which can cause dramatic tissue damage, increased the number of the neurons expressing p-S10H3 [3,4] (see also in Figure 1). In contrast, brief noxious or innoxious stimuli (i.e., $37^{\circ} \mathrm{C}$; moderate pressure or noxious cold) did not result in any sign of central sensitization as assessed by p-S10H3. Thus, this PTM, at least in the spinal cord, seems to be linked to noxious stimulation. Burn injury-induced tissue damage was not assessed in this study, since the original article [50] proved that this model of scalding type thermal stimulus causes severe burn injury, damaging both the epidermis and the dermis of the hind paw. Consequently, the term "tissue damage" through the text refers to the massive histopathological alteration of the skin of the exposed hindlimb in response to the noxious thermal stimulus [50]. It must be noted that the anti-p-S10H3 antibody raised in rabbit produced a dotted staining pattern within the dorsal column of the white matter, however, this did not in any way interfere with the identification of p-S10H3-IR nuclei in the grey matter of the spinal cord. Labeling in the white matter is probably due to non-specific binding of the antibody that is unlikely to be burn injuryrelated phenomena as it could be observed in naive animals, too. While earlier reports indicated that $\mathrm{p}-\mathrm{S} 10 \mathrm{H} 3$ is exclusively expressed in neurons $[3,4]$, we now found that NeuN-immunoreactive p-S10H3-expressing cells made up only $83.5 \%$ of the total p-S10H3 population in the SDH. Some p-S10H3-expressing cells exhibited strong Iba1-IR (3.5\%) in our experiments, but in line with Torres-Perez et al. [4], we also confirmed that astrocytes do not show p-S10H3 upregulation after burn injury (data not shown). Since this dynamic epigenetic tag on histone $\mathrm{H} 3$ tail is rather transient in nature [3,4], to prevent the activity of the endogenous phosphatases and so that $\mathrm{S} 10 \mathrm{H} 3$ would remain to be phosphorylated for a while, a phosphatase inhibitor was added to the paraformaldehyde (PFA) solution during perfusion. Therefore, we assume that our analysis provided unbiased estimates of the proportions of p-S10H3-positive nuclei among different pools of cells. Still, despite of our efforts, the identity of the remaining $~ 10 \%$ of p-S10H3-expressing cells remains to be elucidated.

It is well documented that c-Fos is expressed by NK1R-positive neurons following noxious heat $[12,51,52]$ a high proportion of which are lamina I PNs relaying nociceptive information to supraspinal brain areas [12,53]. Thus, it is reasonable to assume that some of these heat-sensitive PNs might show p-S10H3-mediated transcriptional changes upon burn injury-associated tissue damage. While nearly all lamina I spinoparabrachial neurons express c-Fos upon noxious thermal stimuli [12,54,55], Tochiki et al. [3] found that only $17 \%$ of lamina I NK1R-positive neurons contained nuclear p-S10H3. Since NK1R is also expressed by lamina I interneurons $[29,40,56]$ to assess PNs showing p-S10H3, we retrogradely labeled them from the $\mathrm{LPb}$, where most $(85 \%)$ PNs send collaterals in rodents $[12,53]$. While our finding that $16 \%$ of CTb-labeled projection neurons contained p-S10H3 fits well the results of Tochiki and his coworkers [3], considering also the 5\% share of PNs from the total p-S10H3 SDH population, it is likely that only a small subset of heat-sensitive PNs are directly affected by transcriptional changes induced by burn injury. It cannot be excluded, however, that the proportion of p-S10H3-IR projection neurons 
which directly participate in processing thermal stimulus via $\mathrm{S} 10 \mathrm{H} 3$ phosphorylation was underestimated, since only PNs projecting to the $\mathrm{LPb}$ had been taken into consideration in this study.

Specific ablation of excitatory interneurons in the SDH caused a complete loss of pain and itch sensation, indicating that different subsets of dorsal horn excitatory interneurons contribute to tissue- and nerve injury-induced hypersensitivity [57]. Consistent with our previous study [4], the present findings apparently provide further evidence that the vast majority of the p-S10H3-positive SDH neurons are excitatory based on their Vglut2 content along with a fair contribution of VGAT-positive inhibitory SDH neurons. These results were verified by immunolabeling for antibodies against to the cell-fate determining transcription factors as well (Pax-2 and Lmx1b), which label GABAergic and glutamatergic neurons with non-overlapping manner [6,8,33-37]. The major transcription factors of SDH neurons (Pax-2 and Lmx1b) cover the entire population of neurons showing $\mathrm{p}$ $\mathrm{S} 10 \mathrm{H} 3$ upregulation, while the Vglut2 + VGAT population cover around two thirds of the neurons with burn injury-induced nuclear p-S10H3 expression, leaving $~ 30 \%$ of cells to be unclassified. This discrepancy might be explained by the fact that the VGAT ${ }^{\text {cre }}$ and Vglut ${ }^{\text {cre }}$ knock in mice used in this study were generated by inserting an internal ribosome entry site (IRES)-Cre cassette after the VGAT and Vglut2 stop codons, respectively [58]. The IRES-dependent downstream gene expression is about $50-80 \%$ lower than the expression of the upstream gene [59]. Thus, it is reasonable to speculate, that several VGAT+ or Vglut2+ neurons in these transgenic mice were less able to produce Cre recombinase due to the IRES strategy. Consequently, in hybrid mice (VGAT:tdTomato and Vglut2:tdTomato) the weak Cre expression was not sufficient for activating the reporter tdTomato expression in certain neurons that were unidentified. Thus, it is possible that these VGAT+ or Vglut2+ neurons were activated by the noxious stimulus and expressed p-S10H3, yet they remained tdTomato-negative (VGAT- or Vglut2-negative).

Neuropeptide signaling plays a significant role in spinal somatosensory processing $[5,17-21,43,60]$. Since neurokinin B-, CCK- and neurotensin-expressing cells are all found in the lamina IIi/III border and largely overlap with protein kinase $\mathrm{C}$ gamma $(\mathrm{PKC} \gamma)[5,19,21]$, their contributions to $\mathrm{p}-\mathrm{S} 10 \mathrm{H} 3$ upregulation after burn injury are questioned due to their different laminar distribution. Among the excitatory neurons, somatostatin (SOM), substance P (SP) and GRP-producing neurons are present in the superficial laminae $[5,18,21,22,41]$, however, only SOM co-expressed considerably with p-S10H3 after noxious heat $(60 \%)$. Taking into consideration that SOM-expressing cells account for $\sim 60 \%$ of the excitatory interneurons in the SDH and exhibit a rather heterogenous population expressing multiple types of neuropeptides $[5,8,18,21,22]$, it can be assumed that a more discrete subgroup of excitatory interneurons within this largely heterogenous $\mathrm{SOM}+$ pool takes part in $\mathrm{p}-\mathrm{S} 10 \mathrm{H} 3$ upregulation. According to our preliminary/unpublished observation, nearly a quarter of the $\mathrm{p}-\mathrm{S} 10 \mathrm{H} 3+/ \mathrm{Pdyn}+$ double-labeled neurons were $\mathrm{SOM}+$ as well. This may raise the possibility that, in contrast to a previous description [8], SOM+ neurons showing p-S10H3 upregulation might include the excitatory Pdyn+ population also, at least partially.

By combining ISH for Tac1 or GRP RNAs with immunostaining for p-S10H3, we provided evidence that none of these excitatory neurons are involved in the $\mathrm{p}-\mathrm{S} 10 \mathrm{H} 3-$ mediated pathway following burn injury and consequential tissue damage. In contrast to Gutierrez-Mecinas et al. [18,22], we found that the most intense staining for Tac1 mRNA was detected in neurons distributed throughout the deeper dorsal horn (III-IV). It was confirmed by $\mathrm{Xu}$ and his coworkers [37] that most Tac1 mRNA expressing cells occupy deep laminae, with the remaining few being scattered through superficial laminae in the spinal cord of young (P7) animals. Additionally, ISH data from GENSAT database (www.gensat.org/imagenavigator.jsp?imageID=2738; accessed on 5 October 2020) also enforces our observation. The discrepancy might be due to the use of transgenic animals [18,22] in which the Tac1 gene might have been transiently turned on/off at any stage of development, resulting in ratios different from the ones in wild type animals. 
The above-mentioned neuropeptides have earlier been identified as important players in the processing of different sensory modalities, including nociception. Somatostatin was implicated in the itch pathway via disinhibition [60] and also in acute mechanical pain [43], whereas GRP-mediated signaling is also associated with spinal itch transmission [22], although the latest results show that specific ablation of GRP neurons in the spinal cord has no influence on either itch or pain processing [41].

Other neuropeptides such as neuropeptide FF (NPFF), which has lately been linked to a neurochemical subgroup among the excitatory neurons, and account for $6 \%$ of excitatory interneurons and about $30 \%$ of those co-expressed with phospho (p)-extracellular signalregulated kinase (ERK)1/2 in lamina I and II of the mouse spinal cord after noxious heat stimulus [17], was not examined in this study. However, we found that the great majority (84.7\%) of the p-ERK1/2 immunopositive nuclei exhibited p-S10H3 immunolabeling, but only half of the p-S10H3-IR neurons co-expressed with p-ERK1/2 [4], indicating that these regulatory molecules could be phosphorylated and thus, activated in different subsets of dorsal horn neurons that do not overlap completely. As a consequence, the proportion of NPFF+ cells within the excitatory neuronal population that responded to noxious temperature would be around $2 \%$ (i.e., one third of the $6 \%$ [17]) suggesting that they are unlikely to contribute notably to the development of central sensitization via the p-S10H3 mediated pathway. Further findings that $85 \%$ of NPFF+ neurons were SOM positive and $40 \%$ contained GRP mRNA [17] also support our previous assumption.

Polgar et al. [23] demonstrated that parvalbumin+ neurons do not participate on $\mathrm{c}-\mathrm{Fos} / \mathrm{p}$-ERK upregulation following noxious stimulation, whereas NPY+ and nNOS+ cells responded to a variety on noxious stimuli. Despite receiving direct primary afferent input from nociceptors, at least in the rat [23], nNOS- and NPY-containing inhibitory SDH neurons showed negligible nuclear p-S10H3 upon burn injury. While earlier studies agreed that calretinin-IR neurons are glutamatergic $[16,20]$, recently, around one fourth of inhibitory dorsal horn neurons in the mouse have been reported to be calretinin-positive $[8,42,61]$. In the present study, we found that $8.3 \%$ of $\mathrm{p}-\mathrm{S} 10 \mathrm{H} 3$-expressing neurons showed calretininimmunopositivity in response to burn injury and three quarters of these neurons were glutamatergic, as assessed by immunohistochemistry (IHC) in Vglut2:tdTomato mice. Dynorphinergic (Pdyn) neurons had the largest share of p-S10H3-expressing neurons following burn injury both in wild-type and Pdyn:EGFP transgenic mice $(\sim 63 \%$ and $\sim 42 \%$, respectively) suggesting their key involvement in the development of heat hyperalgesia after burn injury. While we did not make an attempt to confirm it, calretinin+ neurons expressing p-S10H3 are unlikely to be overlapping with the excitatory dynorphin+ population, as suggested by the recent findings of Gutierrez-Mecinas et al. [20].

Inhibitory neurons produce c-Fos or pERK1/2 more readily following noxious heat $[11,18]$ than their excitatory counterparts. In contrast to this observation, on sections from VGAT- or Vglut2:tdTomato transgenic mice, we found that excitatory calretinin+ or Pdyn+ neurons showing p-S10H3 in their nuclei were more numerous in number than inhibitory ones. One possible explanation for the discrepancy between our findings and that of Gutierrez-Mecinas et al. [18] is that $\sim 60 \%$ of p-S10H3-positive neurons co-expressed c-Fos, whereas $\sim 20 \%$ of c-Fos-positive neurons co-expressed p-S10H3 as quantified by Torres-Perez et al. [4]. The remaining p-S10H3-positive neurons that lack c-Fos ( 40\%) presumably belongs to the excitatory subset of SDH neurons.

Early works demonstrated that complete Freund's adjuvant (CFA) injection resulted in prodynorphin and NK1R upregulation through the activation of the mitogen-activated protein kinase (MAPK)/ERK pathway, indicating Pdyn neurons might contribute to acute inflammatory pain hypersensitivity [62,63]. Moreover, many of the dynorphin-containing neurons were shown to express c-Fos after noxious stimulation [64,65]. In accordance with several studies [42-44,66], we found that Pdyn neurons are abundant in laminae I-IIo at the L4-L5 level in mice. Although dynorphinergic neurons in these laminae were found to be mainly inhibitory based upon their Pax-2-IR [37,42] or their GABA-IR [44], an excitatory subset of Pdyn cells was also shown to be present in the SDH of spinal 
cord. In our experiments on L4-L5 sections from Pdyn:EGFP mice approximately 83.3\% of $\mathrm{Pdyn}+\mathrm{SDH}$ neurons that contain p-S10H3 were excitatory based on their Lmx1b-IR. In line with observations in rat [44], we found that non-GABAergic Pdyn neurons (i.e., the Lmx $1 b+$ population) are uniformly distributed throughout the entire superficial laminae (laminae I-IIo) in the mouse spinal cord. Pdyn neurons located more deeply in the dorsal horn, however, were all Pax-2-immunonegative in our experiments, which is in line with earlier findings [42,44]. Accordingly, a recent transcriptomics-based study also identified a cluster of excitatory SDH neurons (Glut14) containing Pdyn [8], although concentrated in deeper laminae.

Galanin-containing neurons have been implicated in cold allodynia [67], thus in line with the recent reports of different inhibitory interneuron populations to be modalityspecific (e.g., pain and itch) [60,68]; our results suggest that the dynorphinergic excitatory group might show a preference to respond to tissue damage induced by burn injury. Inhibitory Pdyn neurons probably respond to a wider range of stimuli, being also involved in spinal itch processing [60] or the spontaneous development of mechanical allodynia [43]. Some projection neurons in lamina I, including heat-selective ones [43], are considered to be dynorphinergic $[69,70]$, thus the few PNs showing p-S10H3 upon burn injury might be Pdyn+. Further studies will be needed to address this. Noxious thermal or chemical stimulation provokes the activation of the endogenous pain control system, involving neuropeptides such as dynorphin and enkephalin via as-yet-unidentified molecular/epigenetic mechanisms [63,64,71]. Our findings that excitatory dynorphinergic cells are activated through the $\mathrm{p}-\mathrm{S} 10 \mathrm{H} 3$ mechanism suggest that this response to burn injury might be part of the activation of the endogenous pain control system. Whether this is a direct activation of SDH dynorphinergic neurons or happens through a spinal cord-brainstem-spinal cord loop remains to be elucidated.

\section{Materials and Methods}

\subsection{Animals and Ethical Considerations}

Experiments were performed on adult (ranging from 2-4 months old) rats and mice of both sexes (see details below in Section 4.2.). Experiments were approved by the Animal Care and Protection Committee at the University of Debrecen (No.: 23-1/2017/DEMÁB) and were performed in accordance with the European Community Council Directives and the IASP Guidelines. Animals were housed individually in a temperature-controlled colony room and maintained on a $12 \mathrm{~h} / 12 \mathrm{~h}$ light/dark cycle. Food and water were provided ad libitum. An Ai14(RCL-tdT)-D reporter line expressing the red fluorescent protein tdTomato in a Cre-dependent manner was purchased from The Jackson Laboratory (JAX; Bar Harbor, ME USA; Stock No. \#021875) [72]. The Cre-mediated excision of the STOP cassette was driven by the Cre recombinase expressed in VGAT ${ }^{\text {cre }}$ or Vglut2 ${ }^{\text {cre }}$ mice in a particular subset of neurons (JAX; \#016962, \#016963) [58]. In the resulting hybrid mice (VGAT:tdTomato and Vglut2:tdTomato), all VGAT- or Vglut2-containing neurons showed strong somatic tdTomato expression. Pdyn-IRES-Cre mice (Pdyn ${ }^{\text {cre, }}$ JAX \#027958) which express Cre recombinase under the direction of the Pdyn (prodynorphin) promoter [73] were crossed with Rosa26-LSL-Cas9 (JAX \#026175) knock in mice having Cre-dependent expression of CRISPR associated protein 9 (cas9) endonuclease and EGFP directed by a CAG promoter [74]. The resulting offspring (Pdyn:EGFP) should have EGFP in all neurons that have expressed Pdyn. Wild-type CD1 mice and Wistar rats were purchased from Charles River Laboratories (Wilmington, MA, USA).

\subsection{Burn Injury Model}

An animal model of burn injury that has been described by White et al. [50], and also by Torres-Perez et al. [4], was applied. Briefly, after inducing deep anesthesia with sodium pentobarbital $(50 \mathrm{mg} / \mathrm{kg}$ intraperitoneal) the left hind leg was immersed into $60{ }^{\circ} \mathrm{C}$ water for $2 \mathrm{~min}$. In control cases, the hind legs were immersed into $37^{\circ} \mathrm{C}$ for $2 \mathrm{~min}$. Five minutes after the burn injury, animals were transcardially perfused with a $4 \%$ 
paraformaldehyde (PFA) solution that contained $0.2 \%$ (wt/vol) sodium fluoride (NaF), a phosphatase inhibitor (Tochiki et al., 2016). A total of eight wild-type CD1 (3 males and 5 females), three Pdyn:EGFP ( 2 males and 1 female), two VGAT:tdTomato ( 2 males), three Vglut2:tdTomato hybrid (1 males and 2 female) mice and six Wistar rats (only males) were used altogether.

\subsection{Retrograde Labeling of SDH Projection Neurons}

For the retrograde labeling of SDH projection neurons, stereotaxic surgery was performed as detailed in previous studies [12,53]. Four Wistar rats (250-300 g) were deeply anaesthetized with a mixture of ketamine and xylazine $(100 \mathrm{mg} / \mathrm{kg}$ and $10 \mathrm{mg} / \mathrm{kg}$, respectively). 200 nanoliters of a cholera toxin b-subunit (CTb; List Biological Labs, Campbell, CA, USA) solution ( $1 \% \mathrm{wt} / \mathrm{vol}$ ) was injected into the right LPb during $5 \mathrm{~min}$ with a $25 \mathrm{uL}$ Hamilton pipette (Hamilton, NV, USA). The following coordinates were used to target the right LPb: $9.12 \mathrm{~mm}$ caudal to the Bregma, $2.4 \mathrm{~mm}$ right to the midline. The depth was $5.8 \mathrm{~mm}$ from the surface of the pia mater [75]. After a survival period of one week, animals were deeply anaesthetized with sodium pentobarbital (50 mg/kg intraperitoneal), exposed to burn injury and transcardially perfused. The side of $\mathrm{CTb}$ injection (right $\mathrm{LPb}$ ) was contralateral to the side of burn injury (left hind leg). L4-L5 segments were used for immunofluorescent staining with the appropriate antibodies (CTb, p-S10H3 and NK1R).

\subsection{Immunoperoxidase Staining}

For the evaluation of the rostrocaudal distribution of $\mathrm{p}-\mathrm{S} 10 \mathrm{H} 3$, the whole lumbar spinal cord (L1-L6) was removed and sectioned with a vibrotome (Leica VT 1000S; Leica, Wetzlar, Germany) at $80 \mu \mathrm{m}$ thickness. Spinal cord segments were identified using vertebral landmarks [27]. After quenching endogenous peroxidase activity with $2 \% \mathrm{H}_{2} \mathrm{O}_{2}$, an antibody raised against $\mathrm{p}-\mathrm{S} 10 \mathrm{H} 3$ in rabbit was added to the samples (1:2000; overnight; $4{ }^{\circ} \mathrm{C}$ ). An ImmPress horseradish peroxidase (HRP) reagent kit (Vector Labs; Burlingame, CA, USA; 2 h; RT) and then a 3,3'-diaminobenzidine (DAB) peroxidase substrate kit (Vector Labs) were used for visualization of the $\mathrm{p}-\mathrm{S} 10 \mathrm{H} 3$ signal.

\subsection{Double and Triple Immunofluorescent Staining}

For the neurochemical characterization, L4-L5 segments were carefully dissected, post-fixed for $3 \mathrm{~h}$ in PFA and sectioned with a cryostat (Leica CM3050 S; Leica) at $100 \mu \mathrm{m}$ thickness. Blocking was carried out with 5\% normal donkey or goat serum (NDS/NGS; Sigma; St. Louis, MO, USA) for an hour followed by incubation in primary (2 days; $4{ }^{\circ} \mathrm{C}$ ) and secondary ( $2 \mathrm{hrs}$ at room temperature, or overnight at $4{ }^{\circ} \mathrm{C}$ ) antibody mixtures. All antibodies were diluted in Na-borohydride-containing phosphate buffer (0.1M PB) supplemented with a $0.3 \%$ Triton-X 100 and $1 \%(v / v)$ appropriate serum. Three 10-minute washes in 0.1 M PB were performed after incubation with all solutions except after the blocking step. Details of the primary antibodies applied in this study are presented in Table 4. Species-specific secondary antibodies were raised in donkey or goat and conjugated to Alexa Fluor-488, 555 and 647 (Invitrogen). At the end of the protocol, cell nucleispecific $4^{\prime}$,6-diamidino-2-phenylindole (DAPI) was added to help determine the laminar boundaries based upon the orientation and density of the nuclei. Sections were mounted in a Hydromount medium (National Diagnostics; Brandon, FL, USA) and confocal images were scanned with Olympus FV3000 confocal systems (Tokyo, Japan).

\subsection{Combination of In Situ Hybridization with Immunofluorescence (ISH/IF)}

ISH was performed using a digoxigenin(DIG)-11-uridine diphosphate (UDP)-labeled cRNA antisense probe for substance P (bases 98-753 of tachykinin 1 (Tac1) mRNA, NCBI accession NM_009311.3) and for GRP (bases 219-643 of GRP mRNA, NCBI accession NM_175012). For the generation of the DIG-labeled RNA probes, we followed the guidelines from Roche (Basel, Switzerland; DIG application manual for non- radioactive in situ hybridization, 4th eds, Chapter 5.). Briefly, total RNA was isolated from the whole 
brainstem of a wild-type (C57Bl/6) mouse, and a cDNA template was generated using random primers following gene-specific PCR. Antisense RNA probes were then generated by in vitro transcription using T7 RNA polymerase on the PCR template. Two anesthetized wild-type CD1 mice were exposed to burn injury and treated with the same fixation procedure described above at the immunohistochemistry. The notable difference was that all surfaces and solutions contacted with the samples or the RNA probes were pretreated with diethyl-pyrocarbonate (DEPC, Sigma-Aldrich) or RNaseZap (Thermo Fisher Sci. Inc. (Waltham, MA, USA).

Free-floating $80-\mu \mathrm{m}$-thick transverse spinal cord sections were digested with Proteinase $\mathrm{K}(2 \mu \mathrm{g} / \mathrm{mL})$, and then incubated with Tac1- or GRP-specific riboprobes (1:200) in hybridization solution for overnight at $60^{\circ} \mathrm{C}$.

After saline-sodium citrate buffer (SSC) stringency washes and RNase A treatment $\left(16 \mu \mathrm{g} / \mathrm{mL}\right.$, for $5 \mathrm{~min}$, at $\left.37^{\circ} \mathrm{C}\right)$, anti-digoxigenin antibody (produced in sheep, 1:1000, Sigma-Aldrich) was added to the slides together with the anti-p-S10H3 antibody raised in rabbit (1:500; overnight at $4{ }^{\circ} \mathrm{C}$ ). After incubation with species-specific secondary antibodies (conjugated to Alexa Fluor-488 or 555; 1:500; overnight at $4{ }^{\circ} \mathrm{C}$ ), cell nuclei-specific DAPI was added $(5 \mu \mathrm{g} / \mathrm{mL} ; 15 \mathrm{~min})$ and sections were mounted in a Hydromount medium. Confocal images were scanned with Olympus FV3000 confocal systems.

\subsection{Imaging and Quantification}

DAB visualized on transverse sections were photographed with a digital camera (Olympus DP72) attached to an upright microscope (Olympus BX51). To evaluate data in an unbiased way, the analysis of the images was carried out by two independent researchers who were "blind" to the experiment. To evaluate the mean number of p-S10H3-positive neurons, the total number of DAB-stained p-S10H3+ nuclei in the SDH was counted in each $100-\mu \mathrm{m}$-thick transverse section and then averaged by spinal segments (L1-L6; Table 1).

To determine the colocalization, confocal image z-stacks consisting of up to 45 optical images at $0.5 \mathrm{um}$ z-separation were scanned with $\times 40$ (UPlanFLN, Olympus, N.A. 1.3) or $\times 60$ (PlanApoN, Olympus, N.A. 1.4) lens from the entire width of the superficial dorsal horn with an Olympus FV3000 confocal system. In all cases, cell nuclei showing a DAPI signal were used as a reference for determining the full thickness of the slices.

To determine $\mathrm{p}-\mathrm{S} 10 \mathrm{H} 3$ expression in $\mathrm{CTb}$-labeled projection neurons, two overlapping image stacks (16-31 optical sections of 1 or $2 \mu \mathrm{m}$ thickness) were acquired with a $\times 10$ (UPlanSApo, Olympus, N.A. 0.4) lens to include the entire dorsal horn. Retrogradelylabeled projection neurons were counted within laminae I-IV of the spinal dorsal horn.

For immunofluorescent studies, the channel corresponding to $\mathrm{p}-\mathrm{S} 10 \mathrm{H} 3$ was viewed first (without a signal the sample was useless for analysis) followed by the other channels. System settings (laser power, confocal aperture and gain) were identical for the experiments when ipsi- and contralateral sides were compared.

Co-localization between p-S10H3 and neurochemical or reporter markers (such as tdTomato) was checked in a $100 \mu \mathrm{m}$-thick band from the surface of the SDH, corresponding to laminae I-IIo, where p-S10H3 nuclei were most abundant, by using the spots module of the Imaris image analysis software (BitPlane, version 8.1.0; Zurich, Switzerland) in surpass mode. This approach allowed one to identify all cells within the entire image volume in 3D defined by up to 45 optical sections at $0.5 \mu \mathrm{m}$ z-separation. The DAPI-stained nuclei were used to unequivocally separate individual cells and to avoid counting the same neuron twice. The region of interest, laminae I and IIo, where p-S10H3 was clustered (a roughly $280 \mu \mathrm{m} \times 100 \mu \mathrm{m}$ band) was isolated by cropping from the original image for further analysis. The channel corresponding to the p-S10H3 was checked and analyzed first, followed by the other channels one by one. Particles in each channel (DAPI-stained nuclei, immunoreactive dots, stained cytoplasm, etc.) were detected and fitted with spots by the automatic detection algorithm of the Imaris software. Filters used by the detection module (labeling quality, intensity center from the DAPI signal, intensity mean for the given channel) were manually adjusted when the default settings did not detect the whole 
range of particles of interest, since the chosen ROIs always contains manageable numbers of cells per sections. With the set parameters, the software module automatically detected all particles within a given channel. Colocalization/proximity between particles in different channels was calculated using a threshold distance of three. The total number of spots/ROI for each channel and number of colocalized spots between two channels were averaged (mean \pm SEM) in Microsoft Excel. Finally, colocalization was expressed as a percentage.

\subsection{Antibody Characterization}

In the present study, two p-S10H3 antibodies (both from Abcam, Cambridge, UK; Table 4) were used to localize p-S10H3 nuclei in the SDH of mice and rats. Both antibodies are validated as ChIP-grade quality and have been referenced in more than 120 publications so far according to company data sheets. We thoroughly compared sections which were reacted with the two anti-p-S10H3 antibodies and found that they resulted in a closeto-identical burn injury-induced p-S10H3 expression pattern in the mouse dorsal horn (Figure S3). Specificity of the p-S10H3 antibodies was confirmed by their colocalization patterns in the ipsilateral side of burn injury and the lack of immunolabeling on the contralateral side of spinal cord (Figure $1 \mathrm{~b}$ and Figure S3). The p-S10H3 antibody produced in rabbits was used in combination with most other primary antibodies (listed in Table 4) throughout the study except for those that were also raised in rabbits: anti-Pax-2, antiLmx1b and anti-somatostatin antibodies (see Table 4). In these cases, the p-S10H3 antibody produced in mice was used. A summary of all antibodies used in this study is shown in Table 4.

Specificity of the goat anti-CTb antibody was previously demonstrated by the lack of any staining in animals not injected with CTb [14,30]. The calcitonin gene-related peptide 1 (CGRP) antibody detects both $\alpha$ and $\beta$ forms of the peptide [14,30]. NK1R-specific antibody was generated in guinea pigs using a peptide corresponding to the $C$-terminal end sequence of the rat NK1R [76]. Biotinylated IB4 was used to identify the IB4-binding subpopulation of non-peptidergic afferents [77]. The monoclonal antibody against calretinin reacts specifically with calretinin in tissue originating from human and rat as determined by its distribution in the brain, as well as by immunoblots [78]. Antibody against parvalbumin labels a subpopulation of neurons in the normal brain with high efficiency but does not stain the brain of parvalbumin knock out mice, according to the supplier. The polyclonal anti-prodynorphin antibody is a synthetic peptide (SQENPNTYSEDLDV) corresponding to amino acids $245-248$ of rat Prodynorphin (Table 4). The polyclonal IBA1 antibody was raised against the synthetic peptide corresponding to AA 134 to 147 from rat IBA1. The monoclonal NeuN antibody was raised against cell nuclei purified from a mouse brain. The antibody against NPY was raised against a synthetic peptide (SDLLMRESTENAPRTR) corresponding to amino acids 76-91 of rat Neuropeptide $Y$. The antibody against nNOS was produced against a synthetic peptide with the sequence ESKKDTDEVFSS, representing the C-terminus of the human protein (residues 1423-1434) according to NP_000611. The polyclonal somatostatin antibody was raised against a synthetic peptide encompassing a sequence within the C-terminus region of the mouse somatostatin. The monoclonal substance $\mathrm{P}$ antibody was produced in rats with epitope mapping near the C-terminus of SP. The antibody against Pax-2 was a GST-Pax-2 fusion protein that was derived from the C-terminal domain (aa188-385) of the murine Pax-2 protein. The anti-Lmx1b antibody was a synthetic peptide within Human LMX1b aa 324-380 (C terminal). The chicken polyclonal antibody to GFP was raised against the recombinant full-length protein corresponding to GFP and it has been referenced more than in 1700 publications. The rat anti-RFP antibody was derived from the hybridoma supernatant. Omission control was routinely performed for all the antibodies.

\subsection{Statistics}

Statistical analyses were performed using Past 4 software [79]. The Mann-Whitney U-test was applied to determine whether the proportion of p-S10H3-IR neurons differed 
significantly between the upper (L4-L6) and the lower (L1-L3) segments of the lumbar spinal cord. After normality tests, paired Student's t-tests were used for comparing the average number of $\mathrm{CTb}$-labeled neurons showing immunoreactivity to various markers (either CTb-IR alone or in combination with p-S10H3- or NK1R-IR) between the ipsiand contralateral side of the burn injury. The Mann-Whitney U-test was also utilized to determine whether the proportion of various populations of $\mathrm{p}-\mathrm{S} 10 \mathrm{H} 3$-expressing neurons differ from each other significantly. Data is expressed as mean \pm standard error of mean unless otherwise stated.

\section{Conclusions}

For the first time, we identified a subset of excitatory dynorphinergic interneurons that are the most affected by burn injury-induced tissue damage and are consequently activated by upregulation of the phosphorylated histone H3-mediated pathway. Based on our results, we propose that this distinct population of excitatory dynorphinergic neurons showing $\mathrm{p}-\mathrm{S} 10 \mathrm{H} 3$ immunoreactivity after noxious heat might have a crucial role during the development of burn injury-associated central sensitization and heat hyperalgesia.

Supplementary Materials: The following are available online at https:/ / www.mdpi.com/1422-006 7/22/5/2297/s1, Figure S1: The termination zone of CGRP-containing peptidergic afferents outlines the area where colocalization analyses was carried out. Figure S2: Validation of the Pdyn:EGFP hybrid strain for neurochemical characterization of dynorphinergic (Pdyn) neurons in the superficial dorsal horn of spinal cord. Figure S3: Verification of the specificity of anti-p-S10H3 antibodies used in the study. Table S1: Distribution of calretinin+ and dynorphin+ neurons showing p-S10H3 in their nuclei, among excitatory and inhibitory SDH neuronal pools, identified by RFP immunoreactivity in VGAT- or Vglut2:tdTomato transgenic mice.

Author Contributions: Conceptualization, A.V. and I.N.; performance of experiments, A.V., Z.M., M.S., B.V., T.B., É.K.; data analysis, A.V., Z.M., P.S.; writing-original draft preparation, A.V.; writingreview and editing, Z.M., I.N., P.S. All authors have read and agreed to the submitted version of the manuscript.

Funding: This project was supported by the National Research, Development and Innovation OfficeNKFIH, FK 125035 (to AV), the János Bolyai Scholarship of the Hungarian Academy of Sciences (to $\mathrm{AV}$ ), the New National Excellence Program of the Ministry of Human Capacities (ÚNKP-18-4-DE-70 and ÚNKP-19-4-DE-3 to AV; ÚNKP-17-3/I to MS) and the Hungarian Brain Research Program (KTIA_NAP_13-2-2014-0005 to AV, MS, ÉK, PSz; 2017-1.2.1-NKP-2017-00002 to MS, ÉK, ZM and PSz).

Institutional Review Board Statement: The study was conducted according to the guidelines of the Declaration of Helsinki, and approved by the Animal Care and Protection Committee at the University of Debrecen (No.: 23-1/2017/DEMÁB) and was performed in accordance with the European Community Council Directives and the IASP Guidelines.

Informed Consent Statement: Not applicable.

Data Availability Statement: The data presented in this study are available upon request.

Acknowledgments: We thank Zita Puskár and Márk Koruzsek for teaching us how to carry out stereotaxic surgery. We are also grateful to Tímea Nánási M. for her technical assistance.

Conflicts of Interest: The authors declare no competing interest. 


\section{Abbreviations}

\begin{tabular}{|c|c|}
\hline CAG & $\begin{array}{l}\text { a hybrid promoter consisting of the cytomegalovirus enhancer fused to } \\
\text { the chicken beta-actin promoter }\end{array}$ \\
\hline cas9 & CRISPR associated protein 9 endonuclease \\
\hline CCK & cholecystokinin \\
\hline CFA & complete Freund's adjuvant \\
\hline CGRP & calcitonin gene-related peptide \\
\hline CONTRA & contralateral \\
\hline CR & calretinin \\
\hline cre & cre recombinase derived from the $\mathrm{P} 1$ bacteriophage \\
\hline cRNA & complementary RNA \\
\hline $\mathrm{CTb}$ & cholera toxin b-subunit \\
\hline $\mathrm{DAB}$ & 3,3'-diaminobenzidine \\
\hline DAPI & $4^{\prime}, 6$-diamidino-2-phenylindole \\
\hline DEPC & diethyl-pyrocarbonate \\
\hline DIG & digoxigenin \\
\hline Dyn & dynorphinergic \\
\hline EGFP & enhanced green fluorescent protein \\
\hline ERK & extracellular signal-regulated kinase \\
\hline GABA & gamma-amino butyric-acid \\
\hline GENSAT & gene expression nervous system atlas \\
\hline GRP & gastrin releasing peptide \\
\hline H3 & histone 3 \\
\hline HRP & horseradish peroxidase \\
\hline IB4 & isolectin B4 \\
\hline Iba1 & ionized calcium binding adaptor molecule 1 \\
\hline IF & immunofluorescence \\
\hline IHC & immunohistochemistry \\
\hline IPSI & ipsilateral \\
\hline IP & immunopositive \\
\hline IR & immunoreactive \\
\hline IRES & internal ribosome entry site \\
\hline ISH & in situ hybridization \\
\hline Lmx1b & LIM homeobox transcription factor 1-beta \\
\hline $\mathrm{LPb}$ & lateral parabrachial nucleus \\
\hline LSL & lox-stop-lox \\
\hline MAPK & mitogen-activated protein kinase \\
\hline NDS or NGS & normal donkey or goat serum \\
\hline NeuN & Fox-3 or Hexaribonucleotide Binding Protein- 3 \\
\hline NK1R & neurokinin-1 receptor \\
\hline Nnos & neuronal nitrogen monoxide synthase \\
\hline NPFF & neuropeptide FF \\
\hline NPY & neuropeptide $Y$ \\
\hline Pax-2 & Paired box gene 2 \\
\hline Pdyn & prodynorphin \\
\hline $\mathrm{p}$-ERK1/2 & phospho-ERK \\
\hline PFA & paraformaldehyde \\
\hline $\mathrm{PKC} \gamma$ & protein kinase $\mathrm{C}$ gamma \\
\hline $\mathrm{PN}$ & projection neuron \\
\hline p-S10H3 & phosphorylation of serine 10 in histone 3 \\
\hline PTM & post-translational modification \\
\hline PV & parvalbumin \\
\hline RFP & red fluorescent protein \\
\hline $\mathrm{SDH}$ & superficial dorsal horn \\
\hline SOM & somatostatin \\
\hline SP & substance $\mathrm{P}$ \\
\hline SSC & saline-sodium citrate buffer \\
\hline Tac1 & the gene for Preprotachykinin-1 \\
\hline UDP-labeled cRNA & uridine diphosphate-labeled cRNA \\
\hline VGAT & vesicular gamma-amino butyric-acid (GABA) transporter \\
\hline Vglut2 & vesicular glutamate transporter 2 \\
\hline
\end{tabular}




\section{References}

1. Sahbaie, P.; Liang, D.Y.; Shi, X.Y.; Sun, Y.; Clark, J.D. Epigenetic regulation of spinal cord gene expression contributes to enhanced postoperative pain and analgesic tolerance subsequent to continuous opioid exposure. Mol. Pain 2016, 12, 1744806916641950. [CrossRef]

2. Khangura, R.K.; Bali, A.; Jaggi, A.S.; Singh, N. Histone acetylation and histone deacetylation in neuropathic pain: An unresolved puzzle? Eur. J. Pharmacol. 2017, 795, 36-42. [CrossRef]

3. Tochiki, K.K.; Maiaru, M.; Norris, C.; Hunt, S.P.; Geranton, S.M. The mitogen and stress-activated protein kinase 1 regulates the rapid epigenetic tagging of dorsal horn neurons and nocifensive behaviour. Pain 2016, 157, 2594-2604. [CrossRef] [PubMed]

4. Torres-Perez, J.V.; Santha, P.; Varga, A.; Szucs, P.; Sousa-Valente, J.; Gaal, B.; Sivado, M.; Andreou, A.P.; Beattie, S.; Nagy, B.; et al. Phosphorylated Histone 3 at Serine 10 Identifies Activated Spinal Neurons and Contributes to the Development of Tissue Injury-Associated Pain. Sci. Rep. 2017, 7, 41221. [CrossRef]

5. Todd, A.J. Identifying functional populations among the interneurons in laminae I-III of the spinal dorsal horn. Mol. Pain 2017, 13, 1744806917693003. [CrossRef] [PubMed]

6. Koch, S.C.; Acton, D.; Goulding, M. Spinal Circuits for Touch, Pain, and Itch. Annu. Rev. Physiol. 2018, 80, 189-217. [CrossRef]

7. Molet, J.; Pohl, M. Gene-based approaches in pain research and exploration of new therapeutic targets and strategies. Eur. J. Pharmacol. 2013, 716, 129-141. [CrossRef]

8. Haring, M.; Zeisel, A.; Hochgerner, H.; Rinwa, P.; Jakobsson, J.E.T.; Lonnerberg, P.; La Manno, G.; Sharma, N.; Borgius, L.; Kiehn, O.; et al. Neuronal atlas of the dorsal horn defines its architecture and links sensory input to transcriptional cell types. Nat. Neurosci. 2018, 21, 869-880. [CrossRef]

9. Xie, Y.F.; Wang, J.; Bonin, R.P. Optogenetic exploration and modulation of pain processing. Exp. Neurol. 2018, 306, 117-121. [CrossRef] [PubMed]

10. Zheng, C.X.; Wang, S.M.; Bai, Y.H.; Luo, T.T.; Wang, J.Q.; Dai, C.Q.; Guo, B.L.; Luo, S.C.; Wang, D.H.; Yang, Y.L.; et al. Lentiviral Vectors and Adeno-Associated Virus Vectors: Useful Tools for Gene Transfer in Pain Research. Anat. Rec. 2018, 301, 825-836. [CrossRef]

11. Todd, A.J.; Spike, R.C.; Brodbelt, A.R.; Price, R.F.; Shehab, S.A. Some inhibitory neurons in the spinal cord develop c-fosimmunoreactivity after noxious stimulation. Neuroscience 1994, 63, 805-816. [CrossRef]

12. Todd, A.J.; Spike, R.C.; Young, S.; Puskar, Z. Fos induction in lamina I projection neurons in response to noxious thermal stimuli. Neuroscience 2005, 131, 209-217. [CrossRef]

13. Polgar, E.; Wright, L.L.; Todd, A.J. A quantitative study of brainstem projections from lamina I neurons in the cervical and lumbar enlargement of the rat. Brain Res. 2010, 1308, 58-67. [CrossRef] [PubMed]

14. Baseer, N.; Al-Baloushi, A.S.; Watanabe, M.; Shehab, S.A.; Todd, A.J. Selective innervation of NK1 receptor-lacking lamina I spinoparabrachial neurons by presumed nonpeptidergic Adelta nociceptors in the rat. Pain 2014, 155, 2291-2300. [CrossRef]

15. Baseer, N.; Polgar, E.; Watanabe, M.; Furuta, T.; Kaneko, T.; Todd, A.J. Projection neurons in lamina III of the rat spinal cord are selectively innervated by local dynorphin-containing excitatory neurons. J. Neurosci. 2012, 32, 11854-11863. [CrossRef]

16. Todd, A.J. Neuronal circuitry for pain processing in the dorsal horn. Nat. Rev. Neurosci. 2010, 11, 823-836. [CrossRef]

17. Gutierrez-Mecinas, M.; Bell, A.; Polgar, E.; Watanabe, M.; Todd, A.J. Expression of Neuropeptide FF Defines a Population of Excitatory Interneurons in the Superficial Dorsal Horn of the Mouse Spinal Cord that Respond to Noxious and Pruritic Stimuli. Neuroscience 2019, 416, 281-293. [CrossRef] [PubMed]

18. Gutierrez-Mecinas, M.; Bell, A.M.; Marin, A.; Taylor, R.; Boyle, K.A.; Furuta, T.; Watanabe, M.; Polgar, E.; Todd, A.J. Preprotachykinin A is expressed by a distinct population of excitatory neurons in the mouse superficial spinal dorsal horn including cells that respond to noxious and pruritic stimuli. Pain 2017, 158, 440-456. [CrossRef]

19. Gutierrez-Mecinas, M.; Bell, A.M.; Shepherd, F.; Polgar, E.; Watanabe, M.; Furuta, T.; Todd, A.J. Expression of cholecystokinin by neurons in mouse spinal dorsal horn. J. Comp. Neurol. 2019, 527, 1857-1871. [CrossRef] [PubMed]

20. Gutierrez-Mecinas, M.; Davis, O.; Polgar, E.; Shahzad, M.; Navarro-Batista, K.; Furuta, T.; Watanabe, M.; Hughes, D.I.; Todd, A.J Expression of Calretinin Among Different Neurochemical Classes of Interneuron in the Superficial Dorsal Horn of the Mouse Spinal Cord. Neuroscience 2019, 398, 171-181. [CrossRef]

21. Gutierrez-Mecinas, M.; Furuta, T.; Watanabe, M.; Todd, A.J. A quantitative study of neurochemically defined excitatory interneuron populations in laminae I-III of the mouse spinal cord. Mol. Pain 2016, 12. [CrossRef] [PubMed]

22. Gutierrez-Mecinas, M.; Polgar, E.; Bell, A.M.; Herau, M.; Todd, A.J. Substance P-expressing excitatory interneurons in the mouse superficial dorsal horn provide a propriospinal input to the lateral spinal nucleus. Brain Struct. Funct. 2018, 223, $2377-2392$. [CrossRef] [PubMed]

23. Polgar, E.; Sardella, T.C.; Tiong, S.Y.; Locke, S.; Watanabe, M.; Todd, A.J. Functional differences between neurochemically defined populations of inhibitory interneurons in the rat spinal dorsal horn. Pain 2013, 154, 2606-2615. [CrossRef]

24. Tiong, S.Y.; Polgar, E.; Van Kralingen, J.C.; Watanabe, M.; Todd, A.J. Galanin-immunoreactivity identifies a distinct population of inhibitory interneurons in laminae I-III of the rat spinal cord. Mol. Pain 2011, 7, 36. [CrossRef]

25. Yasaka, T.; Tiong, S.Y.; Hughes, D.I.; Riddell, J.S.; Todd, A.J. Populations of inhibitory and excitatory interneurons in lamina II of the adult rat spinal dorsal horn revealed by a combined electrophysiological and anatomical approach. Pain 2010, 151, 475-488. [CrossRef] 
26. Zeisel, A.; Hochgerner, H.; Lonnerberg, P.; Johnsson, A.; Memic, F.; Van der Zwan, J.; Haring, M.; Braun, E.; Borm, L.E.; La Manno, G.; et al. Molecular Architecture of the Mouse Nervous System. Cell 2018, 174, 999-1014.e22. [CrossRef] [PubMed]

27. Harrison, M.; O’Brien, A.; Adams, L.; Cowin, G.; Ruitenberg, M.J.; Sengul, G.; Watson, C. Vertebral landmarks for the identification of spinal cord segments in the mouse. NeuroImage 2013, 68, 22-29. [CrossRef] [PubMed]

28. Hunt, S.P.; Rossi, J. Peptide- and non-peptide-containing unmyelinated primary afferents: The parallel processing of nociceptive information. Philos. Trans. R. Soc. Lond. Ser. B Biol. Sci. 1985, 308, 283-289.

29. Nagy, J.I.; Hunt, S.P. The termination of primary afferents within the rat dorsal horn: Evidence for rearrangement following capsaicin treatment. J. Comp. Neurol. 1983, 218, 145-158. [CrossRef]

30. Saeed, A.W.; Ribeiro-da-Silva, A. Non-peptidergic primary afferents are presynaptic to neurokinin-1 receptor immunoreactive lamina I projection neurons in rat spinal cord. Mol. Pain 2012, 8, 64. [CrossRef]

31. Basbaum, A.I.; Bautista, D.M.; Scherrer, G.; Julius, D. Cellular and molecular mechanisms of pain. Cell 2009, 139, 267-284. [CrossRef]

32. Luz, L.L.; Szucs, P.; Pinho, R.; Safronov, B.V. Monosynaptic excitatory inputs to spinal lamina I anterolateral-tract-projecting neurons from neighbouring lamina I neurons. J. Physiol. 2010, 588, 4489-4505. [CrossRef]

33. Balazs, A.; Meszar, Z.; Hegedus, K.; Kenyeres, A.; Hegyi, Z.; Docs, K.; Antal, M. Development of putative inhibitory neurons in the embryonic and postnatal mouse superficial spinal dorsal horn. Brain Struct. Funct. 2017, 222, 2157-2171. [CrossRef]

34. Cheng, L.; Arata, A.; Mizuguchi, R.; Qian, Y.; Karunaratne, A.; Gray, P.A.; Arata, S.; Shirasawa, S.; Bouchard, M.; Luo, P.; et al. Tlx3 and Tlx1 are post-mitotic selector genes determining glutamatergic over GABAergic cell fates. Nat. Neurosci. 2004, 7, 510-517. [CrossRef] [PubMed]

35. Huang, M.; Huang, T.; Xiang, Y.; Xie, Z.; Chen, Y.; Yan, R.; Xu, J.; Cheng, L. Ptf1a, Lbx1 and Pax2 coordinate glycinergic and peptidergic transmitter phenotypes in dorsal spinal inhibitory neurons. Dev. Biol. 2008, 322, 394-405. [CrossRef] [PubMed]

36. Larsson, M. Pax2 is persistently expressed by GABAergic neurons throughout the adult rat dorsal horn. Neurosci. Lett. 2017, 638, 96-101. [CrossRef] [PubMed]

37. Xu, Y.; Lopes, C.; Qian, Y.; Liu, Y.; Cheng, L.; Goulding, M.; Turner, E.E.; Lima, D.; Ma, Q. Tlx1 and Tlx3 coordinate specification of dorsal horn pain-modulatory peptidergic neurons. J. Neurosci. 2008, 28, 4037-4046. [CrossRef] [PubMed]

38. Todd, A.J.; Hughes, D.I.; Polgar, E.; Nagy, G.G.; Mackie, M.; Ottersen, O.P.; Maxwell, D.J. The expression of vesicular glutamate transporters VGLUT1 and VGLUT2 in neurochemically defined axonal populations in the rat spinal cord with emphasis on the dorsal horn. Eur. J. Neurosci. 2003, 17, 13-27. [CrossRef]

39. Chaudhry, F.A.; Reimer, R.J.; Bellocchio, E.E.; Danbolt, N.C.; Osen, K.K.; Edwards, R.H.; Storm-Mathisen, J. The vesicular GABA transporter, VGAT, localizes to synaptic vesicles in sets of glycinergic as well as GABAergic neurons. J. Neurosci. 1998, 18, 9733-9750. [CrossRef]

40. Al Ghamdi, K.S.; Polgar, E.; Todd, A.J. Soma size distinguishes projection neurons from neurokinin 1 receptor-expressing interneurons in lamina I of the rat lumbar spinal dorsal horn. Neuroscience 2009, 164, 1794-1804. [CrossRef]

41. Barry, D.M.; Liu, X.T.; Liu, B.; Liu, X.Y.; Gao, F.; Zeng, X.; Liu, J.; Yang, Q.; Wilhelm, S.; Yin, J.; et al. Exploration of sensory and spinal neurons expressing gastrin-releasing peptide in itch and pain related behaviors. Nat. Commun. 2020, 11, 1397. [CrossRef]

42. Boyle, K.A.; Gutierrez-Mecinas, M.; Polgar, E.; Mooney, N.; O'Connor, E.; Furuta, T.; Watanabe, M.; Todd, A.J. A quantitative study of neurochemically defined populations of inhibitory interneurons in the superficial dorsal horn of the mouse spinal cord. Neuroscience 2017, 363, 120-133. [CrossRef]

43. Duan, B.; Cheng, L.; Bourane, S.; Britz, O.; Padilla, C.; Garcia-Campmany, L.; Krashes, M.; Knowlton, W.; Velasquez, T.; Ren, X.; et al. Identification of spinal circuits transmitting and gating mechanical pain. Cell 2014, 159, 1417-1432. [CrossRef] [PubMed]

44. Sardella, T.C.; Polgar, E.; Garzillo, F.; Furuta, T.; Kaneko, T.; Watanabe, M.; Todd, A.J. Dynorphin is expressed primarily by GABAergic neurons that contain galanin in the rat dorsal horn. Mol. Pain 2011, 7, 76. [CrossRef]

45. Chwang, W.B.; O'Riordan, K.J.; Levenson, J.M.; Sweatt, J.D. ERK/MAPK regulates hippocampal histone phosphorylation following contextual fear conditioning. Learn. Mem. 2006, 13, 322-328. [CrossRef] [PubMed]

46. Crosio, C.; Heitz, E.; Allis, C.D.; Borrelli, E.; Sassone-Corsi, P. Chromatin remodeling and neuronal response: Multiple signaling pathways induce specific histone $\mathrm{H} 3$ modifications and early gene expression in hippocampal neurons. J. Cell Sci. 2003, 116, 4905-4914. [CrossRef] [PubMed]

47. Liang, D.Y.; Li, X.; Clark, J.D. Epigenetic regulation of opioid-induced hyperalgesia, dependence, and tolerance in mice. J. Pain 2013, 14, 36-47. [CrossRef] [PubMed]

48. Gutierrez-Mecinas, M.; Trollope, A.F.; Collins, A.; Morfett, H.; Hesketh, S.A.; Kersante, F.; Reul, J.M. Long-lasting behavioral responses to stress involve a direct interaction of glucocorticoid receptors with ERK1/2-MSK1-Elk-1 signaling. Proc. Natl. Acad. Sci. USA 2011, 108, 13806-13811. [CrossRef]

49. Lorenzo, L.E.; Ramien, M.; St Louis, M.; De Koninck, Y.; Ribeiro-da-Silva, A. Postnatal changes in the Rexed lamination and markers of nociceptive afferents in the superficial dorsal horn of the rat. J. Comp. Neurol. 2008, 508, 592-604. [CrossRef]

50. White, J.P.M.; Ko, C.W.; Fidalgo, A.R.; Cibelli, M.; Paule, C.C.; Anderson, P.J.; Cruz, C.; Gomba, S.; Matesz, K.; Veress, G.; et al. Severe burn injury induces a characteristic activation of extracellular signal-regulated kinase $1 / 2$ in spinal dorsal horn neurons. Eur. J. Pain 2011, 15, 683-690. [CrossRef] 
51. Mantyh, P.W.; DeMaster, E.; Malhotra, A.; Ghilardi, J.R.; Rogers, S.D.; Mantyh, C.R.; Liu, H.; Basbaum, A.I.; Vigna, S.R.; Maggio, J.E.; et al. Receptor endocytosis and dendrite reshaping in spinal neurons after somatosensory stimulation. Science 1995, 268, 1629-1632. [CrossRef] [PubMed]

52. Todd, A.J.; McGill, M.M.; Shehab, S.A. Neurokinin 1 receptor expression by neurons in laminae I, III and IV of the rat spinal dorsal horn that project to the brainstem. Eur. J. Neurosci. 2000, 12, 689-700. [CrossRef]

53. Spike, R.C.; Puskar, Z.; Andrew, D.; Todd, A.J. A quantitative and morphological study of projection neurons in lamina I of the rat lumbar spinal cord. Eur. J. Neurosci. 2003, 18, 2433-2448. [CrossRef] [PubMed]

54. Bester, H.; De Felipe, C.; Hunt, S.P. The NK1 receptor is essential for the full expression of noxious inhibitory controls in the mouse. J. Neurosci. 2001, 21, 1039-1046. [CrossRef]

55. Bester, H.; Matsumoto, N.; Besson, J.M.; Bernard, J.F. Further evidence for the involvement of the spinoparabrachial pathway in nociceptive processes: A c-Fos study in the rat. J. Comp. Neurol. 1997, 383, 439-458. [CrossRef]

56. Cameron, D.; Polgar, E.; Gutierrez-Mecinas, M.; Gomez-Lima, M.; Watanabe, M.; Todd, A.J. The organisation of spinoparabrachial neurons in the mouse. Pain 2015, 156, 2061-2071. [CrossRef]

57. Wang, X.; Zhang, J.; Eberhart, D.; Urban, R.; Meda, K.; Solorzano, C.; Yamanaka, H.; Rice, D.; Basbaum, A.I. Excitatory superficial dorsal horn interneurons are functionally heterogeneous and required for the full behavioral expression of pain and itch. Neuron 2013, 78, 312-324. [CrossRef]

58. Vong, L.; Ye, C.; Yang, Z.; Choi, B.; Chua, S., Jr.; Lowell, B.B. Leptin action on GABAergic neurons prevents obesity and reduces inhibitory tone to POMC neurons. Neuron 2011, 71, 142-154. [CrossRef] [PubMed]

59. Mizuguchi, H.; Xu, Z.; Ishii-Watabe, A.; Uchida, E.; Hayakawa, T. IRES-dependent second gene expression is significantly lower than cap-dependent first gene expression in a bicistronic vector. Mol. Ther. 2000, 1, 376-382. [CrossRef] [PubMed]

60. Kardon, A.P.; Polgar, E.; Hachisuka, J.; Snyder, L.M.; Cameron, D.; Savage, S.; Cai, X.; Karnup, S.; Fan, C.R.; Hemenway, G.M.; et al. Dynorphin acts as a neuromodulator to inhibit itch in the dorsal horn of the spinal cord. Neuron 2014, 82, 573-586. [CrossRef]

61. Smith, K.M.; Boyle, K.A.; Madden, J.F.; Dickinson, S.A.; Jobling, P.; Callister, R.J.; Hughes, D.I.; Graham, B.A. Functional heterogeneity of calretinin-expressing neurons in the mouse superficial dorsal horn: Implications for spinal pain processing. $J$. Physiol. 2015, 593, 4319-4339. [CrossRef]

62. Ji, R.R.; Baba, H.; Brenner, G.J.; Woolf, C.J. Nociceptive-specific activation of ERK in spinal neurons contributes to pain hypersensitivity. Nat. Neurosci. 1999, 2, 1114-1119. [CrossRef] [PubMed]

63. Ji, R.R.; Befort, K.; Brenner, G.J.; Woolf, C.J. ERK MAP kinase activation in superficial spinal cord neurons induces prodynorphin and NK-1 upregulation and contributes to persistent inflammatory pain hypersensitivity. J. Neurosci. 2002, 22, 478-485. [CrossRef]

64. Naranjo, J.R.; Mellstrom, B.; Achaval, M.; Sassone-Corsi, P. Molecular pathways of pain: Fos/Jun-mediated activation of a noncanonical AP-1 site in the prodynorphin gene. Neuron 1991, 6, 607-617. [CrossRef]

65. Noguchi, K.; Kowalski, K.; Traub, R.; Solodkin, A.; Iadarola, M.J.; Ruda, M.A. Dynorphin expression and Fos-like immunoreactivity following inflammation induced hyperalgesia are colocalized in spinal cord neurons. Mol. Brain Res. 1991, 10, 227-233. [CrossRef]

66. Ruda, M.A.; Iadarola, M.J.; Cohen, L.V.; Young, W.S., 3rd. In situ hybridization histochemistry and immunocytochemistry reveal an increase in spinal dynorphin biosynthesis in a rat model of peripheral inflammation and hyperalgesia. Proc. Natl. Acad. Sci. USA 1988, 85, 622-626. [CrossRef] [PubMed]

67. Zhang, M.D.; Barde, S.; Yang, T.; Lei, B.L.; Eriksson, L.I.; Mathew, J.P.; Andreska, T.; Akassoglou, K.; Harkany, T.; Hokfelt, T.G.M.; et al. Orthopedic surgery modulates neuropeptides and BDNF expression at the spinal and hippocampal levels. Proc. Natl. Acad. Sci. USA 2016, 113, E6686-E6695. [CrossRef] [PubMed]

68. Petitjean, H.; Pawlowski, S.A.; Fraine, S.L.; Sharif, B.; Hamad, D.; Fatima, T.; Berg, J.; Brown, C.M.; Jan, L.Y.; Ribeiro-da-Silva, A.; et al. Dorsal Horn Parvalbumin Neurons Are Gate-Keepers of Touch-Evoked Pain after Nerve Injury. Cell Rep. 2015, 13, 1246-1257. [CrossRef]

69. Nahin, R.L.; Hylden, J.L.K.; Iadarola, M.J.; Dubner, R. Peripheral Inflammation Is Associated with Increased Dynorphin Immunoreactivity in Both Projection and Local Circuit Neurons in the Superficial Dorsal Horn of the Rat Lumbar Spinal-Cord. Neurosci. Lett. 1989, 96, 247-252. [CrossRef]

70. Standaert, D.G.; Watson, S.J.; Houghten, R.A.; Saper, C.B. Opioid Peptide Immunoreactivity in Spinal and Trigeminal Dorsal Horn Neurons Projecting to the Parabrachial Nucleus in the Rat. J. Neurosci. 1986, 6, 1220-1226. [CrossRef]

71. Noguchi, K.; Morita, Y.; Kiyama, H.; Sato, M.; Ono, K.; Tohyama, M. Preproenkephalin gene expression in the rat spinal cord after noxious stimuli. Mol. Brain Res. 1989, 5, 227-234. [CrossRef]

72. Madisen, L.; Zwingman, T.A.; Sunkin, S.M.; Oh, S.W.; Zariwala, H.A.; Gu, H.; Ng, L.L.; Palmiter, R.D.; Hawrylycz, M.J.; Jones, A.R.; et al. A robust and high-throughput Cre reporting and characterization system for the whole mouse brain. Nat. Neurosci. 2010, 13, 133-140. [CrossRef] [PubMed]

73. Krashes, M.J.; Shah, B.P.; Madara, J.C.; Olson, D.P.; Strochlic, D.E.; Garfield, A.S.; Vong, L.; Pei, H.J.; Watabe-Uchida, M.; Uchida, N.; et al. An excitatory paraventricular nucleus to AgRP neuron circuit that drives hunger. Nature 2014, $507,238$. [CrossRef] [PubMed]

74. Platt, R.J.; Chen, S.D.; Zhou, Y.; Yim, M.J.; Swiech, L.; Kempton, H.R.; Dahlman, J.E.; Parnas, O.; Eisenhaure, T.M.; Jovanovic, M.; et al. CRISPR-Cas9 Knockin Mice for Genome Editing and Cancer Modeling. Cell 2014, 159, 440-455. [CrossRef] 
75. Paxinos, G.; Watson, C. The Rat Brain in Stereotaxic Coordinates, 2nd ed.; Academic Press: Sydney, Australia; Orlando, FL, USA, 1986; p. 237.

76. Yu, Y.J.; Arttamangkul, S.; Evans, C.J.; Williams, J.T.; Von Zastrow, M. Neurokinin 1 receptors regulate morphine-induced endocytosis and desensitization of mu-opioid receptors in CNS neurons. J. Neurosci. 2009, 29, 222-233. [CrossRef] [PubMed]

77. Veress, G.; Meszar, Z.; Muszil, D.; Avelino, A.; Matesz, K.; Mackie, K.; Nagy, I. Characterisation of cannabinoid 1 receptor expression in the perikarya, and peripheral and spinal processes of primary sensory neurons. Brain Struct. Funct. 2013, 218, 733-750. [CrossRef] [PubMed]

78. Molgaard, S.; Ulrichsen, M.; Boggild, S.; Holm, M.L.; Vaegter, C.; Nyengaard, J.; Glerup, S. Immunofluorescent visualization of mouse interneuron subtypes. F1000Research 2014, 3, 242. [CrossRef]

79. Hammer, O.; Harper, D.A.T.; Ryan, P.D. PAST: Paleontological statistics software package for education and data analysis. Palaeontol. Electron. 2001, 4, 1-9. 